\title{
Enhanced Voltage Control of VSC-HVDC Connected Offshore Wind Farms Based on Model Predictive Control
}

Guo, Yifei; Gao, Houlei; Wu, Qiuwei; Zhao, Haoran; Østergaard, Jacob; Shahidehpour, Mohammad

Published in:

IEEE Transactions on Sustainable Energy

Link to article, DOI:

10.1109/TSTE.2017.2743005

Publication date:

2018

Document Version

Peer reviewed version

Link back to DTU Orbit

Citation (APA):

Guo, Y., Gao, H., Wu, Q., Zhao, H., Østergaard, J., \& Shahidehpour, M. (2018). Enhanced Voltage Control of VSC-HVDC Connected Offshore Wind Farms Based on Model Predictive Control. IEEE Transactions on Sustainable Energy, 9(1). https://doi.org/10.1109/TSTE.2017.2743005

\section{General rights}

Copyright and moral rights for the publications made accessible in the public portal are retained by the authors and/or other copyright owners and it is a condition of accessing publications that users recognise and abide by the legal requirements associated with these rights.

- Users may download and print one copy of any publication from the public portal for the purpose of private study or research.

- You may not further distribute the material or use it for any profit-making activity or commercial gain

- You may freely distribute the URL identifying the publication in the public portal 


\title{
Enhanced Voltage Control of VSC-HVDC Connected Offshore Wind Farms Based on Model Predictive Control
}

\author{
Yifei Guo, Houlei Gao, Member, IEEE, Qiuwei Wu, Senior Member, IEEE, Haoran Zhao, Jacob \\ Østergaard, Senior Member, IEEE, and Mohammad Shahidehpour, Fellow, IEEE
}

\begin{abstract}
This paper proposes an enhanced voltage control strategy (EVCS) based on model predictive control (MPC) for voltage source converter based high voltage direct current (VSCHVDC) connected offshore wind farms (OWFs). In the proposed MPC based EVCS, all wind turbine generators (WTGs) as well as the wind farm side VSC are optimally coordinated to keep voltages within the feasible range and reduce system power losses. Considering the high $R / X$ ratio of the OWF collector system, the effects of active power outputs of WTGs on voltage control are also taken into consideration. The predictive model of VSC with a typical cascaded control structure is derived in details. The sensitivity coefficients are calculated by an analytical method to improve the computational efficiency. A VSC-HVDC connected OWF with 64 WTGs was used to validate the proposed voltage control strategy.
\end{abstract}

Index Terms-model predictive control (MPC), offshore wind farms (OWFs), power loss, voltage control, VSC-HVDC.

\section{INTRODUCTION}

$\mathrm{W}$ IND power has been rapidly developing during last few decades due to the renewable-energy targets set by the governments over the world. A considerable number of large scale wind farms are planned distant from the onshore grid [1]. Compared with conventional submarine high voltage AC transmission, the voltage source converter-based high voltage direct current (VSC-HVDC) transmission system is considered as a suitable way to transport the power from distant offshore wind farms (OWFs) due to various technoeconomic advantages such as independent active and reactive power control, frequency decoupling between OWFs and onshore grids, feasibility of multi-terminal dc grids and inherent black start capability [2]-[3].

This work was supported by the National Key Research and Developmen Program of China under Grant 2016YFB0900603.

Y. Guo and H. Gao are with Key Laboratory of Power System Intelligent Dispatch and Control of Ministry of Education, Shandong University, Jinan 250061, China (e-mail: yfguo_sdu@163.com; houleig@sdu.edu.cn).

Q. Wu is with the Center for Electric and Energy, Department of Electrical Engineering, Technical University of Denmark (DTU), Kgs. Lyngby 2800 Denmark, and School of Electrical Engineering, Shandong University, Jinan 250061, China (e-mail: qw@elektro.dtu.dk).

H. Zhao and J. Østergaard are with Center for Electric and Energy, Department of Electrical Engineering, Technical University of Denmark (DTU), Kgs. Lyngby 2800, Denmark (e-mail: hzhao@elektro.dtu.dk joe@elektro.dtu.dk).

M. Shahidehpour is with the Department of Electrical and Computer Engineering, Illinois Institute of Technology (IIT), Chicago, IL 60616, USA (e-mail: ms@iit.edu).
The increased penetration of wind power in power systems has introduced various challenges towards system operation [4]. To counter the challenges, modern wind farms are required to meet the grid code requirements [5]-[7] set by transmission system operators (TSOs). In conventional AC connected wind farms, the active power and reactive power (Var) control are decoupled [8]. Generally, the active power of wind farms is required to track the reference set by system operators. The total active power is dispatched to individual wind turbine generators (WTGs) by the wind farm active power controller. Several dispatch strategies such as proportional distribution (PD) control, proportional-integral (PI) control and fuzzy control, have been discussed in [9]. Among these, the PD strategy is widely adopted in modern wind farms due to its simple implementation, which also takes into account the available power and Var capability of WTGs [8]-[11]. Reactive power control is related to the voltage regulation of wind farms. Several control modes including voltage, power factor and reactive power at the point of connection (POC) have been specified in many grid codes [12]. Voltage control mode often shows superior performance for transmission systems [13]. In [11], [14], the set-point of reactive power was calculated based on the voltage at the POC and then dispatched to each WTG based on the PD strategy which is similar to the active power dispatch. Centralized and decentralized voltage control schemes were discussed in [15], which are distinguished by the outer control loop of WTGs. The decentralized control scheme performs better considering the negligible delay between wind farm controller and WTGs. In [16], a hierarchical voltage controller was designed and implemented in a wind power base of northern China.

For VSC-HVDC connected OWFs, a considerable number of studies have been done for the fault ride through (FRT) / low voltage ride through (LVRT) control strategies due to the lower short circuit power contribution from power electronic interfaced WTGs and VSCs [17]-[19].

The control strategies based on optimal power flow (OPF) were proposed in [20]-[23]. In [20], the voltage reference of the pilot bus was determined by the offline optimal power flow calculation and the total reactive power reference was obtained using a PI controller and then dispatched to each WTG. In [21]-[23], the objectives of the OPF were the power loss of the OWF collector system, grid side converter (GSC) of WTGs and HVDC converters. Since the VSC-HVDC transmission system decouples the OWFs from the onshore 
AC grid, the main control aim for OWFs is to maintain the terminal voltage of each WTG within the feasible range [16], which was not considered in these OPF-based strategies. Besides, generally, the voltage of POC controlled by wind farm side VSC (WFVSC) is set at the nominal value [24], which may neglect the fast voltage adjustment capability of VSC.

In recent years, Model Predictive Control (MPC), also called receding horizon control, has been extensively applied in the wind power generation system both at the wind turbine level [25]-[28] and wind farm level [13], [29]-[31]. In [25], a model-based predictive controller for power control of doubly fed induction generator (DFIG)-based WTG was proposed using a linearized state-space model. In [26], a new wind power conversion system configuration was explored and a two-step model predictive control strategy was proposed, which optimizes the maximum power point tracking (MPPT), dc-link capacitor voltages balancing, regulation of net dc-bus voltage, etc. In [27], a nonlinear model predictive controller was derived for power control of DFIG, taking into account the unbalanced grid conditions. Similarly, in [28], a direct power control strategies under unbalanced grid voltage conditions was proposed based on MPC. A distributed MPC scheme of a wind farm for optimal active power control using the fast gradient method was proposed in [29]-[30]. The objectives of the wind farm controller are power reference tracking from the system operator and WTG mechanical load minimization. In [13], a MPC-based coordinated wind farm voltage controller was designed to optimally coordinate different fast and slow voltage regulation devices. In [31], a combined power control strategy was proposed to optimize the voltage profile inside the wind farm as well as the fatigue loads of WTGs.

The MPC can be effectively applied in the wind power generation system due to the following advantages:

- The control objective and operating constraints can be explicitly represented in the optimization problem [32];

- It can take into account the dynamic response of the system, consequently, the obtained optimal control input is more effective than that without prediction;

- It is applicable both at the turbine level and farm level and can be designed with different time scales.

- It is suitable to optimally coordinate various Var devices in a wind farm with different time constants [13], [31].

The main contribution of this paper is a MPC based enhanced voltage control strategy (MPC-EVCS) design for VSC-HVDC connected OWFs. The WFVSC and WTGs are optimally coordinated in this strategy. The impacts of active power output of WTGs on voltage variation are also taken into consideration to improve the voltage control performance. The predictive VSC model with the common cascaded control structure is developed. The sensitivity coefficients with respect to power injections and slack bus voltage are derived based on an analytical method. Compared to the existing control strategies, the proposed strategy can regulate voltages while also taking into account economic operation of the OWFs. And the fast and flexible voltage regulation capability of the VSC can be fully used. Besides, the active and reactive power outputs of WTGs are optimally coordinated to achieve better control performance.

The rest of this paper is organized as follows. In Section II, the concept of the proposed MPC-EVCS is presented. In Section III, the sensitivity calculation method is introduced. In Section IV, the predictive models of VSC and WTGs are developed. The mathematical formulation of the MPC-EVCS is presented in Section V. Section VI presents the case studies followed by conclusions.

\section{MPC BASEd ENHANCEd Voltage CONTROL StRATEGY FOR VSC-HVDC CONNECTED OWFS}

\section{A. Configuration of the VSC-HVDC Connected OWFs}

Fig. 1 shows the typical configuration of a VSC-HVDC connected OWF, which is connected to the onshore external $400 \mathrm{kV}$ AC grid through a $\pm 150 \mathrm{kV}$ VSC-HVDC system with nominal power rating of $400 \mathrm{MW}$. The OWF is comprised of two parts. Each part is equipped with a collector substation, and the substations are connected to a common VSC station through $150 \mathrm{kV}$ submarine cables. The WTGs are connected by eight medium voltage (MV) $33 \mathrm{kV}$ collector cables. There are eight full-scale-converter 6.25 MW WTGs at each feeder, referred to as a string. The WTGs are placed with a distance of $1.5 \mathrm{~km}$.

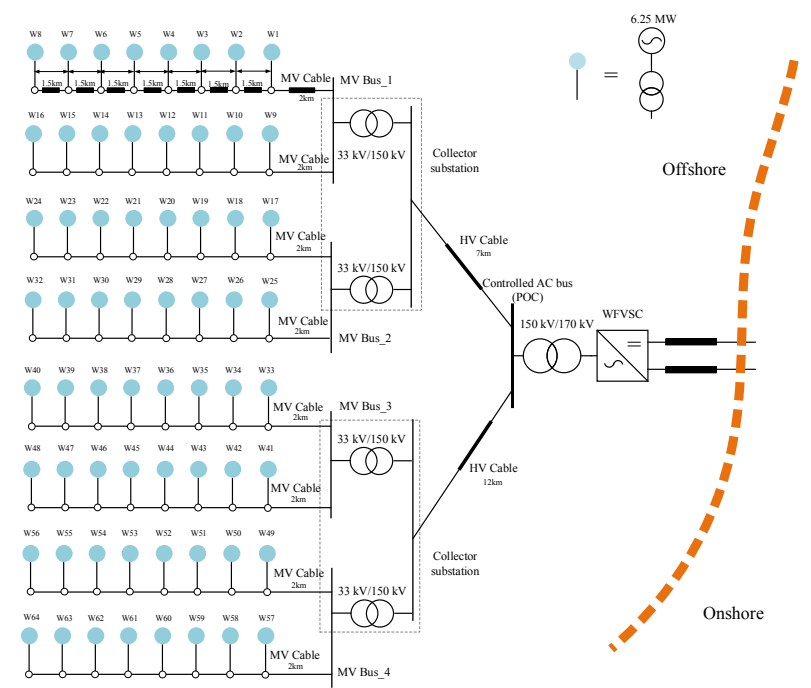

Fig. 1. Configuration of a VSC-HVDC connected OWF.

\section{B. Concept of the MPC-EVCS}

The structure of the MPC controller is illustrated in Fig. 2. In the proposed MPC controller, there are two control modes designed for different operation conditions: 1) normal mode, and 2) corrective mode. In the first control mode, all bus voltages are within the feasible range. The control objective is to minimize voltage deviations of the key buses, reduce system power losses and optimize the active power distribution of WTGs. In the corrective mode, the control objective is to correct the bus voltage which violates the limits. A dynamic weighting coefficient allocation method according to the degree of voltage deviation is used to regulate the voltage more effectively. The details of the proposed MPC- 
EVCS are presented in Section V. To be noticed, the control period of the proposed EVCS is in seconds. Considering the real-life implementation, the coordination between the EVCS and existing FRT control scheme [17]-[20] of a wind farm should be in place. The FRT control should have the highest priority. Once one unit triggers the FRT control strategy, the EVCS will be locked. The control mode will switch to the FRT control mode. A voltage dead-band can be designed to coordinate these two control strategies.

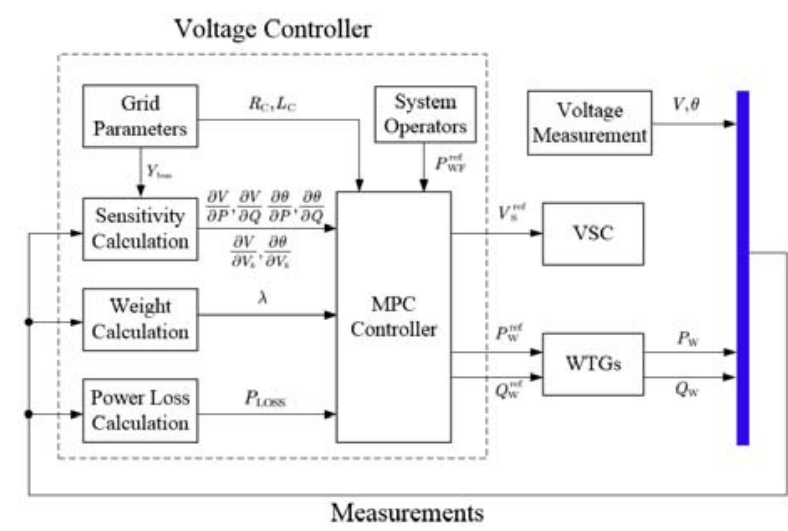

Fig. 2. Structure of the OWF voltage control.

\section{Sensitivity COEFFICIENT CALCUlation}

The calculation of voltage sensitivity, active power losses sensitivity and Var limit sensitivity of WTGs is presented in this section.

\section{A. Voltage Sensitivity}

In the typical optimal control problems, the updated Jacobian matrix is commonly used to derive the voltage sensitivity coefficients. From the computational point of view, the main disadvantage of this method is that the Jacobian matrix should be rebuilt and inverted for every change in operation conditions of the network, which involves nontrivial computation constraints for the implementation in realtime control problems. Moreover, this method cannot be used to calculate the sensitivity coefficients with respect to slack bus voltage. Thus, an efficient analytical sensitivity calculation method, which was initially used in radial distribution network, is used in this paper to improve the computation efficiency [33].

Considering a network comprised of $N$ buses ( $N_{\mathrm{S}}$ slack buses and $N_{\mathrm{PQ}}$ buses with $P Q$ injections). $\mathcal{S}$ and $\mathcal{N}$ denote the sets of slack buses and the buses with $P Q$ injections, respectively, i.e., $\mathcal{S} \cup \mathcal{N}=\{1,2, \ldots, N\}$ with $\mathcal{S} \cap \mathcal{N}=\varnothing$. Define $\bar{V}_{i} \triangleq V_{i} e^{\mathrm{j} \theta_{i}}$ for all buses and $\bar{S}_{i}=P_{i}+\mathrm{j} Q_{i}$ for $i \in \mathcal{N}$. The link between bus voltages and power injections is

$$
\underline{S}_{i}=\underline{V}_{i} \sum_{j \in \mathcal{S} \cup \mathcal{N}} \bar{Y}_{\text {bus }, i j} \bar{V}_{j}
$$

where $\underline{V}_{i}$ and $\underline{S}_{i}$ denote the conjugates of $\bar{V}_{i}$ and $\bar{S}_{i}$, respectively; $\quad Y_{\text {bus }}=\left[\bar{Y}_{\text {bus }, i j}\right]_{N \times N}$ denotes the admittance matrix.

\section{a. Sensitivity coefficients with respect to power injections}

To derive the voltage magnitude and phase angle sensitivity coefficients with respect to power injections, the partial derivatives of $\underline{S}_{i}(i \in \mathcal{N})$ with respect to active power $P_{l}$ and reactive power $Q_{l}$ of a bus $l \in \mathcal{N}$ have to be calculated, which satisfy the following equations:

$$
\begin{aligned}
\frac{\partial \underline{S}_{i}}{\partial P_{l}}=\frac{\partial\{P-\mathrm{j} Q\}}{\partial P_{l}} & =\frac{\partial \underline{V}_{i}}{\partial P_{l}} \sum_{j \in \mathcal{S} \cup \mathcal{N}} \bar{Y}_{\mathrm{bus}, i j} \bar{V}_{j} \\
& +\bar{V}_{i} \sum_{j \in \mathcal{N}} \bar{Y}_{\mathrm{bus}, i j} \frac{\partial \bar{V}_{j}}{\partial P_{l}}= \begin{cases}1, & \text { for } i=l \\
0, & \text { for } i \neq l\end{cases} \\
\frac{\partial \underline{S}_{i}}{\partial Q_{l}}=\frac{\partial\{P-\mathrm{j} Q\}}{\partial Q_{l}}= & \frac{\partial \underline{V}_{i}}{\partial Q_{l}} \sum_{j \in \mathcal{S} \cup \mathcal{N}} \bar{Y}_{\mathrm{bus}, i j} \bar{V}_{j} \\
& +\bar{V}_{i} \sum_{j \in \mathcal{N}} \bar{Y}_{\mathrm{bus}, i j} \frac{\partial \bar{V}_{j}}{\partial Q_{l}}= \begin{cases}-\mathrm{j} 1, & \text { for } i=l \\
0, & \text { for } i \neq l\end{cases}
\end{aligned}
$$

Equation (2) is linear with respect to $\partial \bar{V}_{i} / \partial P_{l}$ and $\partial \underline{V}_{i} / \partial P_{l}$. Equation (3) is linear with respect to $\partial \bar{V}_{i} / \partial Q_{l}$ and $\partial \underline{V}_{i} / \partial Q_{l}$. According to the theorem in [33], (2) and (3) have a unique solution for radial network.

Once $\partial \bar{V}_{i} / \partial P_{l}, \partial \underline{V}_{i} / \partial P_{l}, \partial \bar{V}_{i} / \partial Q_{l}$ and $\partial \underline{V}_{i} / \partial Q_{l}$ are obtained, the voltage magnitude and phase angle sensitivity can be computed by,

$$
\begin{aligned}
& \frac{\partial V_{i}}{\partial P_{l}}=\frac{1}{V_{i}} \operatorname{Re}\left(\underline{V}_{i} \frac{\partial \bar{V}_{i}}{\partial P_{l}}\right), \frac{\partial \theta_{i}}{\partial P_{l}}=\frac{1}{V_{i}^{2}} \operatorname{Im}\left(\underline{V}_{i} \frac{\partial \bar{V}_{i}}{\partial P_{l}}\right) \\
& \frac{\partial V_{i}}{\partial Q_{l}}=\frac{1}{V_{i}} \operatorname{Re}\left(\underline{V}_{i} \frac{\partial \bar{V}_{i}}{\partial Q_{l}}\right), \frac{\partial \theta_{i}}{\partial Q_{l}}=\frac{1}{V_{i}^{2}} \operatorname{Im}\left(\underline{V}_{i} \frac{\partial \bar{V}_{i}}{\partial Q_{l}}\right)
\end{aligned}
$$

\section{b. Sensitivity coefficients with respect to slack bus voltage}

For a bus $i \in \mathcal{N}$, the partial derivatives with respect to voltage magnitude $V_{k}$ of a slack bus $k \in \mathcal{S}$ are derived by,

$$
-\bar{V}_{i} \bar{Y}_{\mathrm{bus}, i k} e^{\mathrm{j} \theta_{k}}=\underline{W}_{i k} \sum_{j \in \mathcal{S} \cup \mathcal{N}} \bar{Y}_{\mathrm{bus}, i j} \bar{V}_{j}+\underline{V}_{i} \sum_{j \in \mathcal{N}} \bar{Y}_{\mathrm{bus}, i j} \bar{W}_{j k}
$$

where

$$
\bar{W}_{i k}=\frac{\partial \bar{V}_{i}}{\partial V_{k}}=\left(\frac{1}{V_{i}} \frac{\partial V_{i}}{\partial V_{k}}+\mathrm{j} \frac{\partial \theta_{i}}{V_{k}}\right) \bar{V}_{i} .
$$

Equation (6) is linear with respect to $\bar{W}_{i k}$ and $\underline{W}_{i k}$, and also has a unique solution. By solving it, the sensitivity coefficients with respect to the slack bus voltage magnitude at bus $k$ are calculated by,

$$
\frac{\partial V_{i}}{\partial V_{k}}=V_{i} \operatorname{Re}\left(\frac{\bar{W}_{i k}}{\bar{V}_{i}}\right), \frac{\partial \theta_{i}}{\partial V_{k}}=\operatorname{Im}\left(\frac{\bar{W}_{i k}}{\bar{V}_{i}}\right) .
$$

\section{B. Active Power Losses Sensitivity}

The power losses of the grid (cables and transformers) and power losses of the converters (GSCs of WTGs and WFVSC) are considered in the paper.

\section{a. Power losses of grid}

The partial derivatives of power losses with respect to voltage magnitude and phase angle can be calculated by, 


$$
\begin{aligned}
& \frac{\partial P_{\mathrm{Grid}}^{\mathrm{LOSS}}}{\partial V_{i}}=2 \sum_{j=1}^{N} V_{j} G_{j i} \cos \theta_{j i}, \\
& \frac{\partial P_{\mathrm{Grid}}^{\mathrm{LOSS}}}{\partial \theta_{i}}=2 \sum_{j=1}^{N} V_{i} V_{j} G_{j i} \sin \theta_{j i} .
\end{aligned}
$$

where $G_{i j}$ is the real part of $\bar{Y}_{i j}$ and $\theta_{j i}=\theta_{j}-\theta_{i}$.

Then, the sensitivity with respect to power output of WTGs and terminal voltage of WFVSC can be calculated by combing (4)-(8), which is as follows

$$
\frac{\partial P_{\mathrm{Grid}}^{\mathrm{LOSS}}}{\partial y}=\frac{\partial P_{\mathrm{Grid}}^{\mathrm{LOSS}}}{\partial V} \cdot \frac{\partial V}{\partial y}+\frac{\partial P_{\mathrm{Grid}}^{\mathrm{LOSS}}}{\partial \theta} \cdot \frac{\partial \theta}{\partial y},
$$

where $y$ represents the active/reactive power output of WTGs and terminal voltage of WFVSC (the slack bus voltage).

\section{b. Power losses of converters}

The GSC of each WTG and HVDC converters are twolevel VSCs. The converter loss can be approximated by a quadratic function depending on the converter current $I_{\mathrm{C}}$ (in p.u.) [21],

$$
\begin{gathered}
P_{\mathrm{Conv}}^{\mathrm{LOSS}}=\left(a+b\left(\frac{I_{\mathrm{Conv}}}{I_{\mathrm{R}}}\right)+c\left(\frac{I_{\mathrm{Conv}}}{I_{\mathrm{R}}}\right)^{2}\right) S_{\mathrm{Conv}}, \\
I_{\mathrm{Conv}}=\frac{\sqrt{P_{\mathrm{Conv}}^{2}+Q_{\mathrm{Conv}}^{2}}}{V_{\mathrm{Conv}}},
\end{gathered}
$$

where $I_{\mathrm{R}}$ is the rated converter current, $S_{\text {Conv }}$ denotes the nominal capacity. $P_{\text {Conv }}, Q_{\text {Conv }}$, and $V_{\text {Conv }}$ are the power injections and terminal voltage. $a, b$, and $c$ are the converter loss parameters which are presented in Appendix B.

According to (11), the converter loss is related to the power injections and terminal voltage. Considering the terminal voltage is always around 1.0 p.u during normal operation, its impacts are neglected, and then the converter loss sensitivity can be calculated by,

$$
\begin{aligned}
\frac{\partial P_{\mathrm{Conv}}^{\mathrm{LOSS}}}{\partial P_{\mathrm{Conv}}} & =\frac{\partial P_{\mathrm{Conv}}^{\mathrm{LOSS}}}{\partial I_{\mathrm{Conv}}} \cdot \frac{\partial I_{\mathrm{Conv}}}{\partial P_{\mathrm{Conv}}} \\
& =\left(\frac{b}{I_{\mathrm{R}}}+2 c \frac{I_{\mathrm{Conv}}}{I_{\mathrm{R}}}\right) S_{\mathrm{Conv}} \cdot \frac{P_{\mathrm{Conv}}}{V_{\mathrm{Conv}} \sqrt{P_{\mathrm{Conv}}^{2}+Q_{\mathrm{Conv}}^{2}}}
\end{aligned}
$$

$$
\begin{aligned}
\frac{\partial P_{\mathrm{Conv}}^{\mathrm{LOSS}}}{\partial Q_{\mathrm{Conv}}} & =\frac{\partial P_{\mathrm{Conv}}^{\mathrm{LOSS}}}{\partial I_{\mathrm{Conv}}} \cdot \frac{\partial I_{\mathrm{Conv}}}{\partial Q_{\mathrm{Conv}}} \\
& =\left(\frac{b}{I_{\mathrm{R}}}+2 c \frac{I_{\mathrm{Conv}}}{I_{\mathrm{R}}}\right) S_{\mathrm{Conv}} \cdot \frac{Q_{\mathrm{Conv}}}{V_{\mathrm{Conv}} \sqrt{P_{\mathrm{Conv}}^{2}+Q_{\mathrm{Conv}}^{2}}}
\end{aligned}
$$

The total system power losses can be calculated by,

$$
P_{\mathrm{LOSS}}=P_{\mathrm{Grid}}^{\mathrm{LOSS}}+P_{\mathrm{WFVSC}}^{\mathrm{LOSS}}+\sum_{i=1}^{N_{\mathrm{W}}} P_{\mathrm{GSC}_{i}}^{\mathrm{LOSS}},
$$

\section{Var Limit Sensitivity of WTGs}

For a full-scale converter WTG, the Var capability limit $\left[Q_{\mathrm{W}}^{\min }, Q_{\mathrm{W}}^{\max }\right]$ depends on its active power output and terminal voltage. In this paper, a look-up table of the $P Q$ capacity curve is used and the sensitivity coefficients are approximately calculated using the linear interpolation method [31].

\section{PRedictive Modeling}

In this section, the predictive models of WFVSC and WTGs are presented which are used for the MPC.

\section{A. Modeling of WTGs}

For a full-scale converter WTG, the control of active and reactive power is decoupled by the full-scale converter. Suppose the active and reactive power references and current measurements of the WTG are $P_{\mathrm{W}}^{\mathrm{ref}}, Q_{\mathrm{W}}^{\mathrm{ref}}, P_{\mathrm{W}}\left(t_{0}\right)$ and $Q_{\mathrm{W}}\left(t_{0}\right)$ where $t_{0}$ is the current time, $\Delta P_{\mathrm{W}}^{\mathrm{ref}}=P_{\mathrm{W}}^{\mathrm{ref}}-P_{\mathrm{W}}\left(t_{0}\right)$ and $\Delta Q_{\mathrm{W}}^{\mathrm{ref}}=Q_{\mathrm{W}}^{\mathrm{ref}}-Q_{\mathrm{W}}\left(t_{0}\right)$. Considering the effects of time delay of the communication system and dynamic response of the WTG control system, the dynamic behavior of the power control loops of WTGs could be described by a first-order lag function [13], [15],

$$
\begin{aligned}
& \Delta P_{\mathrm{W}}=\frac{1}{1+s T_{\mathrm{W}}^{P}} \Delta P_{\mathrm{W}}^{\mathrm{ref}} \\
& \Delta Q_{\mathrm{W}}=\frac{1}{1+s T_{\mathrm{W}}^{Q}} \Delta Q_{\mathrm{W}}^{\mathrm{ref}}
\end{aligned}
$$

where $T_{\mathrm{W}}^{\mathrm{P}}$ and $T_{\mathrm{w}}^{\mathrm{Q}}$ are the time constants, which are in the range of $1 \sim 10 \mathrm{~s}$ [34]. Accordingly, the continuous state space of a wind farm with $N_{\mathrm{W}}$ WTGs can be formulated as,

$$
\begin{aligned}
& \Delta \dot{P}_{\mathrm{W}}=A_{\mathrm{W}}^{P} \Delta P_{\mathrm{W}}+B_{\mathrm{W}}^{P} \Delta P_{\mathrm{W}}^{\mathrm{ref}}, \\
& \Delta \dot{Q}_{\mathrm{W}}=A_{\mathrm{W}}^{Q} \Delta Q_{\mathrm{W}}+B_{\mathrm{W}}^{Q} \Delta Q_{\mathrm{W}}^{\mathrm{ref}},
\end{aligned}
$$

where

$$
\begin{aligned}
& \Delta P_{\mathrm{W}}=\left[\Delta P_{\mathrm{W}_{1}}, \Delta P_{\mathrm{W}_{2}}, \cdots, \Delta P_{\mathrm{W}_{N_{\mathrm{W}}}}\right]^{\mathrm{T}}, \\
& \Delta P_{\mathrm{W}}^{\mathrm{ref}}=\left[\Delta P_{\mathrm{W}_{1}}^{\mathrm{ref}}, \Delta P_{\mathrm{W}_{2}}^{\mathrm{ref}}, \cdots, \Delta P_{\mathrm{W}_{N_{\mathrm{W}}}}^{\mathrm{ref}}\right]^{\mathrm{T}} \\
& \Delta Q_{\mathrm{W}}=\left[\Delta Q_{\mathrm{W}_{1}}, \Delta Q_{\mathrm{W}_{2}}, \cdots, \Delta Q_{\mathrm{W}_{N_{\mathrm{W}}}}\right]^{\mathrm{T}}, \\
& \Delta Q_{\mathrm{W}}^{\mathrm{ref}}=\left[\Delta Q_{\mathrm{W}_{1}}^{\mathrm{ref}}, \Delta Q_{\mathrm{W}_{2}}^{\mathrm{ref}}, \cdots, \Delta Q_{\mathrm{W}_{N_{\mathrm{W}}}}^{\mathrm{ref}}\right]^{\mathrm{T}}, \\
& A_{\mathrm{W}}^{P}=\operatorname{diag}\left(-1 / T_{\mathrm{W}_{1}}^{P},-1 / T_{\mathrm{W}_{2}}^{P}, \cdots,-1 / T_{\mathrm{W}_{N_{\mathrm{W}}}}^{P}\right), \\
& B_{\mathrm{W}}^{P}=\operatorname{diag}\left(1 / T_{\mathrm{W}_{1}}^{P}, 1 / T_{\mathrm{W}_{2}}^{P}, \cdots, 1 / T_{\mathrm{W}_{N_{\mathrm{W}}}}^{P}\right), \\
& A_{\mathrm{W}}^{Q}=\operatorname{diag}\left(-1 / T_{\mathrm{W}_{1}}^{Q},-1 / T_{\mathrm{W}_{2}}^{Q}, \cdots,-1 / T_{\mathrm{W}_{N_{\mathrm{W}}}}^{Q}\right), \\
& B_{\mathrm{W}}^{Q}=\operatorname{diag}\left(1 / T_{\mathrm{W}_{1}}^{Q}, 1 / T_{\mathrm{W}_{2}}^{Q}, \cdots, 1 / T_{\mathrm{W}_{N_{\mathrm{W}}}}^{Q}\right) .
\end{aligned}
$$

\section{B. Modeling of WFVSC}

The structure of WFVSC station with a standard cascaded control structure, i.e., inner current control loop and outer control loop, is illustrated in Fig. 3. The control strategy of the outer loop is the AC voltage magnitude control which is often adopted in OWF integration. The phase reactor and converter transformer are represented together by $Z_{\mathrm{c}}=R_{\mathrm{c}}+\mathrm{j} \omega L_{\mathrm{c}}$. The 
mathematical model of the system in the synchronized rotating dq reference frame is,

$$
\begin{aligned}
& L_{\mathrm{c}} \frac{d i_{\mathrm{c}}^{\mathrm{d}}}{d t}=-R_{\mathrm{c}} i_{\mathrm{c}}^{\mathrm{d}}+\omega L_{\mathrm{c}} i_{\mathrm{c}}^{\mathrm{q}}+u_{\mathrm{s}}^{\mathrm{d}}-u_{\mathrm{c}}^{\mathrm{d}}, \\
& L_{\mathrm{c}} \frac{d i_{\mathrm{c}}^{\mathrm{q}}}{d t}=-R_{\mathrm{c}} i_{\mathrm{c}}^{\mathrm{q}}+\omega L_{\mathrm{c}} i_{\mathrm{c}}^{\mathrm{d}}+u_{\mathrm{s}}^{\mathrm{q}}-u_{\mathrm{c}}^{\mathrm{q}}, \\
& C_{\mathrm{f}} \frac{d u_{\mathrm{s}}^{\mathrm{d}}}{d t}=i_{\mathrm{s}}^{\mathrm{d}}-i_{\mathrm{c}}^{\mathrm{d}}+\omega C_{\mathrm{f}} u_{\mathrm{s}}^{\mathrm{q}}, \\
& C_{\mathrm{f}} \frac{d u_{\mathrm{s}}^{\mathrm{q}}}{d t}=i_{\mathrm{s}}^{\mathrm{q}}-i_{\mathrm{c}}^{\mathrm{q}}-\omega C_{\mathrm{f}} u_{\mathrm{s}}^{\mathrm{d}} .
\end{aligned}
$$

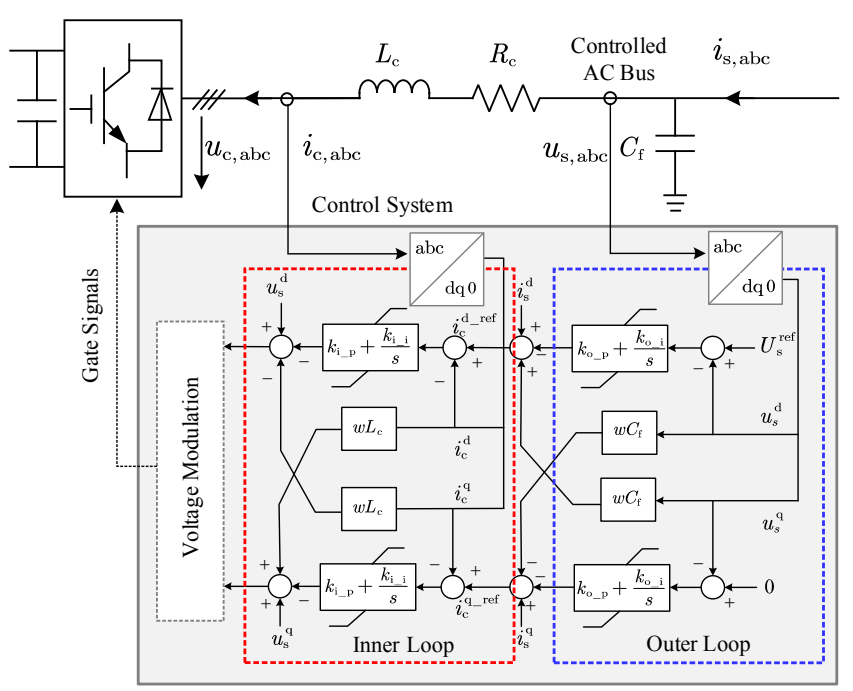

Fig. 3. Cascaded control structure of WFVSC.

The whole system comprised of the physical model of VSC and control system can be decoupled in the dq frame through the decoupling terms $\left(\Delta u_{\mathrm{c}}^{\mathrm{d}}=\omega L_{\mathrm{c}} i_{\mathrm{c}}^{\mathrm{q}}, \Delta u_{\mathrm{c}}^{\mathrm{q}}=-\omega L_{\mathrm{c}} i_{\mathrm{c}}^{\mathrm{d}}\right.$ for the inner loop and $\Delta i_{\mathrm{s}}^{\mathrm{d}}=\omega C_{\mathrm{f}} u_{\mathrm{s}}^{\mathrm{q}}, \Delta i_{\mathrm{s}}^{\mathrm{q}}=-\omega C_{\mathrm{f}} u_{\mathrm{s}}^{\mathrm{d}}$ for the outer loop). According to the control strategy, the disturbance in the q-axis can be neglected, i.e., $U_{\mathrm{s}}=\sqrt{\left(u_{\mathrm{s}}^{\mathrm{d}}\right)^{2}+\left(u_{\mathrm{s}}^{\mathrm{q}}\right)^{2}} \approx u_{\mathrm{s}}^{\mathrm{d}}$ [35]. And the control performance of the inner loop can be improved by selecting suitable parameters of the PI controller, which can be determined by,

$$
\begin{aligned}
& k_{\mathrm{i} \_\mathrm{p}_{\mathrm{p}}}=\frac{L_{\mathrm{c}}}{T_{\mathrm{inr}}}, \\
& k_{\mathrm{i} \_\mathrm{i}_{\mathrm{i}}}=\frac{R_{\mathrm{c}}}{T_{\mathrm{inr}}}
\end{aligned}
$$

where $k_{\mathrm{i}_{-} \mathrm{p}}$ and $k_{\mathrm{i}_{\mathrm{i}}}$ are the proportional and integral gains of the PI controllers of the inner loop, respectively. $T_{\mathrm{inr}}$ is the desired closed loop time constant for the inner current control loop. Generally, $T_{\mathrm{inr}}$ is chosen between 5 10 times slower than the switching frequency. Considering the fast dynamic response capability of the inner control loop, the disturbances of $i_{\mathrm{s}}^{\mathrm{d}}$ and $u_{\mathrm{s}}^{\mathrm{q}}$ are be approximately compensated by the compensating terms. Thus, the WFVSC system model can be simplified as shown in Fig. 4. The time delay can be modelled by a first-order lag function with a time constant of $T_{\mathrm{d}}$.

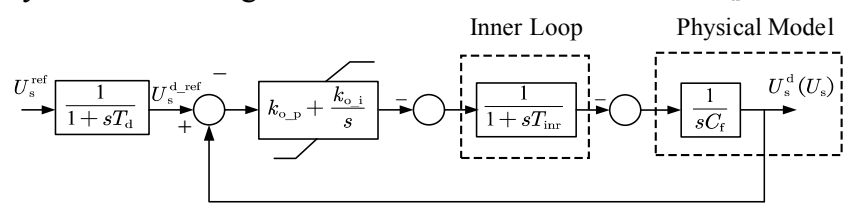

Fig. 4. AC voltage control loop of the WFVSC.

Introducing a state variable $\Delta i_{\mathrm{PI}}^{\mathrm{d}}$, the state space model of WFVSC can be described by,

$$
\begin{gathered}
\Delta u_{\mathrm{s}-}^{\mathrm{d} \_ \text {ref }}=\frac{1}{1+s T_{\mathrm{d}}} \Delta U_{\mathrm{s}}^{\mathrm{ref}}, \\
\Delta u_{\mathrm{s}}^{\mathrm{d}}=-\frac{1}{s C_{\mathrm{f}}} \Delta i_{\mathrm{PI}}^{\mathrm{d}}, \\
\Delta u_{\text {int }}^{\mathrm{d}}=\frac{\Delta u_{\mathrm{s}}^{\mathrm{d} \_ \text {ref }}-\Delta u_{\mathrm{s}}^{\mathrm{d}}}{s}, \\
\Delta i_{\mathrm{PI}}^{\mathrm{d}}=-\frac{1}{1+s T_{\mathrm{inr}}}\left(k_{\mathrm{o} \_\mathrm{p}}+\frac{k_{\mathrm{o} \_\mathrm{i}}}{s}\right)\left(\Delta u_{\mathrm{s}}^{\mathrm{d} \_ \text {ref }}-\Delta u_{\mathrm{s}}^{\mathrm{d}}\right),
\end{gathered}
$$

with

$$
\begin{aligned}
& \Delta U_{\mathrm{s}}=U_{\mathrm{s}}-U_{\mathrm{s}}\left(t_{0}\right), \\
& \Delta U_{\mathrm{c}}=U_{\mathrm{c}}-U_{\mathrm{c}}\left(t_{0}\right), \\
& \Delta u_{\mathrm{s}}^{\mathrm{d} \_ \text {ref }}=u_{\mathrm{s}}^{\mathrm{d} \_r e f}-u_{\mathrm{s}}^{\mathrm{d} \_ \text {ref }}\left(t_{0}\right), \\
& \Delta u_{\mathrm{s}}^{\mathrm{d}}=u_{\mathrm{s}}^{\mathrm{d}}-u_{\mathrm{s}}^{\mathrm{d}}\left(t_{0}\right), \\
& \Delta u_{\text {int }}^{\mathrm{d}}=\frac{u_{\mathrm{s}}^{\mathrm{d} \_ \text {ref }}-u_{\mathrm{s}}^{\mathrm{d}}}{s},
\end{aligned}
$$

where $U_{\mathrm{s}}^{\mathrm{ref}}$ and $U_{\mathrm{s}}$ are the voltage reference from the MPC controller and voltage of POC, respectively; $U_{\mathrm{c}}$ is the voltage at the VSC terminal; $s$ denotes the complex variable; $k_{\mathrm{o} \_\mathrm{p}}$ and $k_{\mathrm{o} \text { i }}$ are the proportional and integral gains of the PI controllers of the outer control loop, respectively.

Represent the state space by a matrix form,

$$
\Delta \dot{x}_{\mathrm{C}}=A_{\mathrm{C}} \Delta x_{\mathrm{C}}+B_{\mathrm{C}} \Delta u_{\mathrm{C}},
$$

where

$$
\begin{aligned}
\Delta x_{\mathrm{C}}= & {\left[\Delta u_{\mathrm{s}}^{\mathrm{d} \_}{ }^{\mathrm{ref}}, \Delta u_{\mathrm{s}}^{\mathrm{d}}, \Delta u_{\mathrm{int}}^{\mathrm{d}}, \Delta i_{\mathrm{PI}}^{\mathrm{d}}\right]^{\mathrm{T}}, \Delta u_{\mathrm{C}}=\left[\Delta U_{\mathrm{s}}^{\mathrm{ref}}\right], } \\
A_{\mathrm{C}}= & {\left[\begin{array}{cccc}
-\frac{1}{T_{\mathrm{d}}} & 0 & 0 & 0 \\
0 & 0 & 0 & \frac{1}{C_{\mathrm{f}}} \\
1 & -1 & 0 & 0 \\
-\frac{k_{\mathrm{o} \_\mathrm{p}}}{T_{\mathrm{inr}}} & \frac{k_{\mathrm{o} \_\mathrm{p}}}{T_{\mathrm{inr}}} & -\frac{k_{\mathrm{o} \_\mathrm{i}}}{T_{\mathrm{inr}}} & -\frac{1}{T_{\mathrm{inr}}}
\end{array}\right], B_{\mathrm{C}}=\left[\begin{array}{c}
\frac{1}{T_{\mathrm{d}}} \\
0 \\
0 \\
0
\end{array}\right] . }
\end{aligned}
$$

\section{Modeling of the Whole System}

For the phasor analysis presented in following sections, the VSC can be regarded as a slack bus of the offshore AC grid (i.e. $\bar{V}_{\mathrm{C}}=V_{\mathrm{C}} e^{\mathrm{j} 0}$ ) and $\bar{V}_{\mathrm{S}}=V_{\mathrm{S}} e^{\mathrm{j} \theta_{\mathrm{S}}}$ denotes the voltage at the 
controlled AC bus. $V_{\mathrm{S}}$ and $V_{\mathrm{C}}$ are equal to $U_{\mathrm{s}}$ and $U_{\mathrm{c}}$ in per unit, respectively. To predict the changes of voltages in the grid, the slack bus voltage should be predicted firstly. Due to the fast tracking capability of the control system of the VSC, the d-axis voltage $u_{\mathrm{s}}^{\mathrm{d}}$ can quickly track the reference $U_{\mathrm{s}}^{\text {ref }}$. The controlled AC bus voltage $\bar{V}_{\mathrm{S}}$ can be affected by the converter terminal voltage $\bar{V}_{\mathrm{C}}$ and the WTGs power outputs. Assuming the sensitivity coefficients are constant during the prediction horizon, a linearized model around the operating point is used to predict the voltage changes, which is expressed as,

$$
\Delta V_{\mathrm{S}} \approx \frac{\partial V_{\mathrm{S}}}{\partial P_{\mathrm{W}}} \Delta P_{\mathrm{W}}+\frac{\partial V_{\mathrm{S}}}{\partial Q_{\mathrm{W}}} \Delta Q_{\mathrm{W}}+\frac{\partial V_{\mathrm{S}}}{\partial V_{\mathrm{C}}} \Delta V_{\mathrm{C}},
$$

where $\partial V_{\mathrm{S}} / \partial P_{\mathrm{W}}, \partial V_{\mathrm{S}} / \partial Q_{\mathrm{W}}$ and $\partial V_{\mathrm{S}} / \partial V_{\mathrm{C}}$ are the sensitivity coefficients. Then, $\Delta V_{\mathrm{C}}$ can be inversely derived using (24).

So far, the continuous state space model of the whole system comprised of $N_{\mathrm{W}}$ WTGs and a WFVSC can be formulated as,

$$
\begin{aligned}
& \Delta \dot{x}=A \Delta x+B \Delta u \\
& \Delta y=C \Delta x
\end{aligned}
$$

where

$$
\begin{aligned}
& \Delta x=\left[\Delta x_{1}, \Delta x_{2}, \ldots, \Delta x_{N_{x}}\right]^{\mathrm{T}}=\underbrace{\left[\Delta u_{\mathrm{s}}^{\mathrm{d} \_}{ }^{\mathrm{ref}}, \Delta u_{\mathrm{s}}^{\mathrm{d}}, \Delta u_{\mathrm{int}}^{\mathrm{d}}, \Delta i_{\mathrm{d}}^{\mathrm{PI}}\right.}_{\Delta x_{\mathrm{C}}}, \\
& \underbrace{\Delta P_{\mathrm{W}_{1}}, \Delta P_{\mathrm{W}_{2}}, \ldots, \Delta P_{\mathrm{W}_{N_{\mathrm{W}}}}}_{\Delta P_{\mathrm{W}}}, \underbrace{\Delta Q_{\mathrm{W}_{1}}, \Delta Q_{\mathrm{W}_{2}}, \ldots, \Delta Q_{\mathrm{W}_{N_{\mathrm{W}}}}}_{\Delta Q_{\mathrm{W}}}]^{\mathrm{T}}, \\
& \Delta u=\left[\Delta u_{1}, \Delta u_{2}, \ldots, \Delta u_{N_{u}}\right]^{\mathrm{T}} \\
& =\left[\Delta V_{\mathrm{S}}^{\mathrm{ref}}, \Delta P_{\mathrm{W}_{1}}^{\mathrm{ref}}, \ldots, \Delta P_{\mathrm{W}_{N_{\mathrm{W}}}}^{\mathrm{ref}}, \Delta Q_{\mathrm{W}_{1}}^{\mathrm{ref}}, \ldots, \Delta Q_{\mathrm{W}_{N_{\mathrm{W}}}}^{\mathrm{ref}}\right]^{\mathrm{T}}, \\
& \Delta y=\left[\Delta y_{1}, \Delta y_{2}, \ldots, \Delta y_{N_{y}}\right]^{\mathrm{T}} \\
& =\left[\Delta V_{\mathrm{C}}, \Delta P_{\mathrm{W}_{1}}, \ldots, \Delta P_{\mathrm{W}_{N_{\mathrm{W}}}}, \Delta Q_{\mathrm{W}_{1}}, \ldots, \Delta Q_{\mathrm{W}_{N_{\mathrm{W}}}}\right]^{\mathrm{T}}, \\
& A=\left[\begin{array}{ccc}
A_{\mathrm{C}} & & \\
& A_{\mathrm{W}}^{P} & \\
& & A_{\mathrm{W}}^{Q}
\end{array}\right], B=\left[\begin{array}{ccc}
B_{\mathrm{C}} & & \\
& B_{\mathrm{W}}^{P} & \\
& & B_{\mathrm{W}}^{Q}
\end{array}\right] \text {, } \\
& C=\left[\begin{array}{lll}
C_{1} & C_{2} & C_{3} \\
& C_{4} & \\
& & C_{5}
\end{array}\right]
\end{aligned}
$$

with

$$
\begin{aligned}
& C_{1}=-\left(\frac{\partial V_{\mathrm{S}}}{\partial V_{\mathrm{C}}}\right)^{-1}[0,-1,0,0], C_{4}=C_{5}=I_{N_{\mathrm{W}}}, \\
& C_{2}=-\left(\frac{\partial V_{\mathrm{S}}}{\partial V_{\mathrm{C}}}\right)^{-1}\left[\frac{\partial V_{\mathrm{S}}}{\partial P_{\mathrm{W}_{1}}}, \frac{\partial V_{\mathrm{S}}}{\partial P_{\mathrm{W}_{2}}}, \cdots, \frac{\partial V_{\mathrm{S}}}{\partial P_{\mathrm{W}_{N_{\mathrm{W}}}}}\right]
\end{aligned}
$$

$$
C_{3}=-\left(\frac{\partial V_{\mathrm{S}}}{\partial V_{\mathrm{C}}}\right)^{-1}\left[\frac{\partial V_{\mathrm{S}}}{\partial Q_{\mathrm{W}_{1}}}, \frac{\partial V_{\mathrm{S}}}{\partial Q_{\mathrm{W}_{2}}}, \cdots, \frac{\partial V_{\mathrm{S}}}{\partial Q_{\mathrm{W}_{N_{W}}}}\right]
$$

Based on the continuous time model, the discrete time state space model with sampling time $\Delta T_{\mathrm{P}}$ can be expressed as,

$$
\begin{aligned}
\Delta x(k+1) & =G \Delta x(k)+H \Delta u(k) \\
\Delta y(k) & =C \Delta x(k)
\end{aligned}
$$

where

$$
G=e^{A \Delta T_{\mathrm{P}}}, H=\int_{0}^{\Delta T_{\mathrm{P}}} e^{A \tau} B \mathrm{~d} \tau
$$

\section{Formulation of MPC Based Enhanced Voltage CONTROL}

In this section, the mathematical formulation of the MPC based EVCS for OWFs is presented. The main objective of the EVCS is to track the power reference given by TSOs and maintain the terminal voltages all WTGs within the specified limits. Moreover, the economical operation is taken into consideration. Consequently, two control modes are designed for different operating conditions.

\section{A. MPC Principle}

MPC is a widely used control method. In MPC, the control input is obtained by solving a discrete-time optimal control problem over a given horizon. An optimal control input sequence is produced and only the first control in the sequence is applied [32].

The principle of MPC used in this paper is graphically illustrated in Fig. 5. For wind farm voltage control, $T_{\mathrm{C}}$ is normally in seconds, which is large than the fast Var devices. To capture the fast dynamics of the system, the sampling time $\Delta T_{\mathrm{P}}$ should be smaller than the control period $T_{\mathrm{C}}$. The suitable prediction horizon $T_{\mathrm{P}}$ is determined by the dynamic performance of the control system. The performance of MPC heavily depends on the selection of $T_{\mathrm{P}}$. If $T_{\mathrm{P}}$ is too large, the accuracy of sensitivity coefficients might decrease and the computational burdens will be increased. If $T_{\mathrm{P}}$ is too small, dynamics cannot be well coordinated [13].

For a prediction horizon, the total control steps, number of prediction steps within one control period and total prediction steps are $N_{\mathrm{C}}=T_{\mathrm{P}} / T_{\mathrm{C}}, N_{\mathrm{S}}=T_{\mathrm{C}} / \Delta T_{\mathrm{P}}$ and $N_{\mathrm{P}}=T_{\mathrm{P}} / \Delta T_{\mathrm{P}}$, respectively. The control actions are only changed at the beginning of the control period and maintained within the control period. 


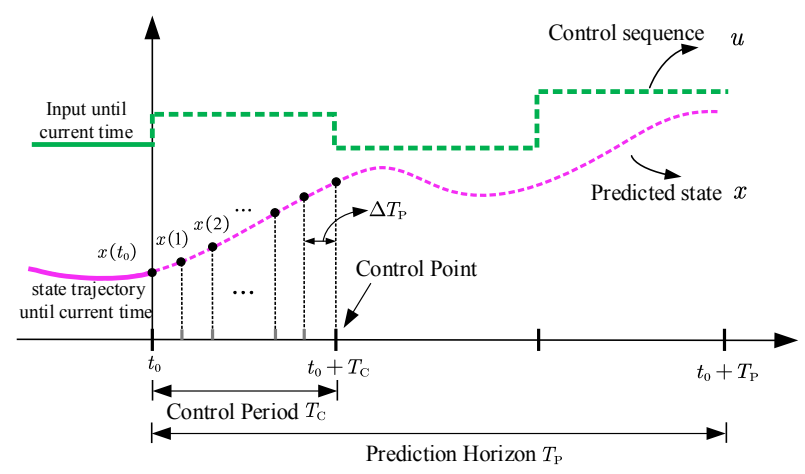

Fig. 5 Principle of MPC.

\section{B. Cost Function}

The cost functions of the two control modes are presented as follows.

\section{a. Normal mode}

If the terminal voltages of all WTGs and MV bus voltages are within its feasible range, i.e., $\left\|V_{\mathrm{W}}-V_{\mathrm{W}}^{\mathrm{ref}}\right\|<V_{\mathrm{W}}^{\text {th }}$ and $\left\|V_{\mathrm{MV}}-V_{\mathrm{MV}}^{\mathrm{ref}}\right\|<V_{\mathrm{MV}}^{\mathrm{th}}$, the control system will operate in the normal mode. $V_{\mathrm{W}}^{\mathrm{ref}}$ and $V_{\mathrm{MV}}^{\mathrm{ref}}$ are the nominal voltage (typically 1.0 p.u.). $V_{\mathrm{MV}}^{\mathrm{th}}$ and $V_{\mathrm{w}}^{\mathrm{th}}$ refer to the threshold value. The voltages, power losses and active power distribution are optimized in this mode.

1) Objective 1: The first objective is voltage regulation. According to the theorem in [36], the OWF presented in Fig. 1 can be divided into several subzones for voltage regulation. Two radial feeders with a common root MV bus can be regarded as an isolate voltage regulation zone. The MV root buses (MV_1 MV_4 in Fig. 1) can be considered as the pilot buses of the subzones. Since the voltage of pilot bus can reflect the voltage conditions of the subzone, in the normal mode, the cost function of voltage regulation in MPC can be described by,

$$
\mathrm{Obj}_{\mathrm{V}}=\sum_{k=1}^{N_{\mathrm{P}}}\left\|\Delta V_{\mathrm{MV}}^{\mathrm{pre}}(k)\right\|^{2}
$$

with

$$
\Delta V_{\mathrm{MV}}^{\mathrm{pre}}=\left[\Delta V_{\mathrm{MV}_{1}}^{\mathrm{pre}}, \Delta V_{\mathrm{MV}_{2}}^{\mathrm{pre}}, \cdots, \Delta V_{\mathrm{MV}_{N_{\mathrm{MV}}}}^{\mathrm{pre}}\right]^{\mathrm{T}},
$$

where $\Delta V_{\mathrm{MV}_{i}}^{\mathrm{pre}}$ is the predictive value of voltage deviation of bus $\mathrm{MV}_{-} i$ to its reference value $V_{\mathrm{MV}}^{\mathrm{ref}}$, and $N_{\mathrm{MV}}$ is the total number of MV buses. Since the WTGs and VSC can affect voltage deviations of $\mathrm{MV}$ buses, the predictive value $\Delta V_{\mathrm{MV}_{i}}^{\mathrm{pre}}$ can be calculated by,

$$
\begin{aligned}
\Delta V_{\mathrm{MV}_{i}}^{\mathrm{pre}}(k)= & V_{\mathrm{MV}_{i}}\left(t_{0}\right)+\frac{\partial V_{\mathrm{MV}_{i}}}{\partial P_{\mathrm{W}}} \Delta P_{\mathrm{W}}(k) \\
& +\frac{\partial V_{\mathrm{MV}_{i}}}{\partial Q_{\mathrm{W}}} \Delta Q_{\mathrm{W}}(k)+\frac{\partial V_{\mathrm{MV}_{i}}}{\partial V_{\mathrm{C}}} \Delta V_{\mathrm{C}}(k)-V_{\mathrm{MV}}^{\mathrm{ref}}(28)
\end{aligned}
$$

where $V_{\mathrm{MV}_{i}}\left(t_{0}\right)$ is the measurement of $i$-th MV bus voltage at current time $t_{0}$.

2) Objective 2: Secondly, the active power losses are optimized in this mode, i.e.,

$$
\operatorname{Obj}_{\mathrm{L}}=\sum_{k=1}^{N_{\mathrm{P}}}\left\|P_{\mathrm{LOSS}}^{\mathrm{pre}}(k)\right\|^{2}
$$

The predictive value of active power losses can be calculated by,

$$
\begin{aligned}
P_{\mathrm{LOSS}}^{\mathrm{pre}}(k)=\frac{\partial P_{\mathrm{LOSS}}}{\partial P_{\mathrm{W}}} \Delta P_{\mathrm{W}}(k) & +\frac{\partial P_{\mathrm{LOSS}}}{\partial Q_{\mathrm{W}}} \Delta Q_{\mathrm{W}}(k) \\
& +\frac{\partial P_{\mathrm{LOSS}}}{\partial V_{\mathrm{C}}} \Delta V_{\mathrm{C}}(k)+P_{\mathrm{LOSS}}^{\mathrm{pre}}\left(t_{0}\right)
\end{aligned}
$$

where $V=\left[V_{1}, V_{2}, \ldots, V_{N}\right]^{\mathrm{T}}, \theta=\left[\theta_{1}, \theta_{2}, \ldots, \theta_{N}\right]^{\mathrm{T}}$ and the sensitivity matrix is presented in Appendix B.

3) Objective 3: Thirdly, considering the active power dispatch based on the PD strategy has the advantage of taking into consideration the maximum available power of WTGs while also optimizing the Var capacity of each WTG, the active power of each WTG shall be dispatched as close as possible to its PD based reference. Thus, the third cost function can be described by,

$$
\operatorname{Obj}_{\mathrm{P}}=\sum_{k=1}^{N_{\mathrm{P}}}\left\|\Delta P_{\mathrm{W}}^{\mathrm{PD}}(k)\right\|^{2} \text {. }
$$

The predictive value $\Delta P_{\mathrm{W}}^{\mathrm{PD}}$ can be calculated by

$$
\Delta P_{\mathrm{W}}^{\mathrm{PD}}(k)=P_{\mathrm{W}}\left(t_{0}\right)+\Delta P_{\mathrm{W}}(k)-P_{\mathrm{W}}^{\mathrm{PD} \_ \text {ref }},
$$

where $P_{\mathrm{W}}^{\mathrm{PD} \_ \text {ref }}=\left[P_{\mathrm{W}_{1}}^{\mathrm{PD} \_ \text {ref }}, P_{\mathrm{W}_{2}{ }^{\mathrm{PD}}{ }^{\mathrm{Pref}}}^{\mathrm{P}}, \ldots, P_{\mathrm{W}_{N_{\mathrm{W}}}}^{\mathrm{PD} \_ \text {ref }}\right]$.

According to (27), (29) and (31), the cost function of normal mode can be expressed by,

$$
\min \left(\lambda_{\mathrm{V}} \mathrm{Obj}_{\mathrm{V}}+\lambda_{\mathrm{L}} \mathrm{Obj}_{\mathrm{L}}+\lambda_{\mathrm{P}} \mathrm{Obj}_{\mathrm{P}}\right),
$$

where $\lambda_{\mathrm{V}}, \lambda_{\mathrm{L}}$ and $\lambda_{\mathrm{P}}$ are the weighting coefficients for $\mathrm{Obj}_{\mathrm{V}}$, $\mathrm{Obj}_{\mathrm{L}}$ and $\mathrm{Obj}_{\mathrm{P}}$, respectively.

\section{b. Corrective mode}

The corrective mode is designed as a back-up mode. If any voltage violates the threshold, the control system will switch to the corrective mode. In this mode, only the voltages are considered as control objective. Define $\Delta V_{\mathrm{W}}^{\mathrm{pre}}=\left[\Delta V_{\mathrm{W}_{1}}^{\mathrm{pre}}\right.$, $\left.\Delta V_{\mathrm{W}_{2}}^{\mathrm{pre}}, \cdots, \Delta V_{\mathrm{W}_{N_{\mathrm{W}}}}^{\mathrm{pre}}\right]^{\mathrm{T}}$, the cost function is,

$$
\min \sum_{k=1}^{N_{\mathrm{P}}}\left(\left\|\Delta V_{\mathrm{W}}^{\mathrm{pre}}(k)\right\|_{\Lambda_{\mathrm{W}}}^{2}+\left\|\Delta V_{\mathrm{MV}}^{\mathrm{pre}}(k)\right\|_{\Lambda_{\mathrm{MV}}}^{2}\right)
$$

where $\lambda_{\mathrm{W}}=\operatorname{diag}\left(\lambda_{\mathrm{W}_{1}}, \lambda_{\mathrm{W}_{2}}, \cdots \lambda_{\mathrm{W}_{N_{\mathrm{W}}}}\right)$ and $\lambda_{\mathrm{MV}}=\operatorname{diag}\left(\lambda_{\mathrm{MV}_{1}}\right.$, $\left.\lambda_{\mathrm{MV}_{2}}, \ldots, \lambda_{\mathrm{MV}_{N_{\mathrm{MV}}}}\right)$ denote the weighting coefficient matrixes. The predictive voltage deviations to its reference $V_{\mathrm{W}}^{\text {ref }}$ can be calculated by,

$$
\begin{aligned}
\Delta V_{\mathrm{W}_{i}}^{\mathrm{pre}}(k)= & V_{\mathrm{W}_{i}}\left(t_{0}\right)+\frac{\partial V_{\mathrm{W}_{i}}}{\partial P_{\mathrm{W}}} \Delta P_{\mathrm{W}}(k) \\
& +\frac{\partial V_{\mathrm{W}_{i}}}{\partial Q_{\mathrm{W}}} \Delta Q_{\mathrm{W}}(k)+\frac{\partial V_{\mathrm{W}_{i}}}{\partial V_{\mathrm{C}}} \Delta V_{\mathrm{C}}(k)-V_{\mathrm{W}}^{\mathrm{ref}}(35)
\end{aligned}
$$

In order to correct the voltages efficiently, the weighting coefficients are determined through a dynamic allocation approach according to the degree of voltage deviations with a 
deadband, as illustrated in Fig. 6. When the absolute value of voltage deviation is less than 0.01 p.u., the weighting factor is set as zero. Once it exceeds 0.01 p.u., the weighting factor is linear with respect to the voltage deviation value. Compared with the normal mode, the WTGs and WFVSC can be fully optimized to contribute to voltage regulation in this mode.

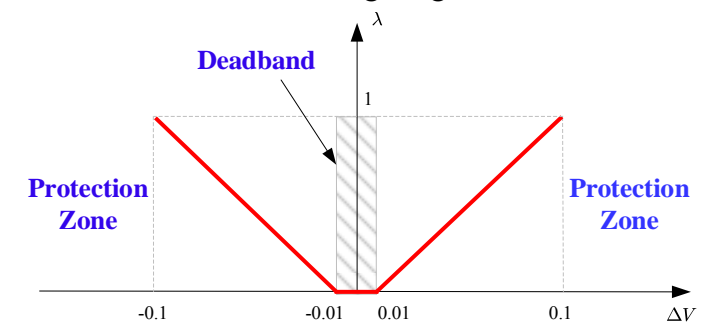

Fig. 6 Dynamic weighting coefficients.

\section{Constraints}

1) WTG Constraints: The active and reactive power of WTGs are constrained as follows,

$$
\begin{gathered}
0 \leqslant P_{\mathrm{W}_{i}}(k) \leqslant P_{\mathrm{W}_{i}}^{\mathrm{av}}, \\
Q_{\mathrm{W}_{i}}^{\min }(k) \leqslant Q_{\mathrm{W}_{i}}(k) \leqslant Q_{\mathrm{W}_{i}}^{\max }(k), \\
i=1,2, \cdots, N_{\mathrm{W}}, k=1,2, \cdots, N_{\mathrm{P}} .
\end{gathered}
$$

where $P_{\mathrm{W}_{i}}^{\text {avi }}$ is the available wind power, $Q_{\mathrm{W}_{i}}^{\min }(k)$ and $Q_{\mathrm{W}_{i}}^{\max }(k)$ are the minimum and maximum Var capacity of WTGs, respectively. $Q_{\mathrm{W}_{i}}^{\min }(k)$ and $Q_{\mathrm{W}_{i}}^{\max }(k)$ are affected by the terminal voltage magnitude and active power output of the WTG, which can be predicted based on a linearized method,

$$
\begin{gathered}
Q_{\mathrm{W}_{i}}^{\min }(k) \approx Q_{\mathrm{W}_{i}}^{\min }\left(t_{0}\right)+\frac{\partial Q_{\mathrm{W}}^{\min }}{\partial P_{\mathrm{W}}} \Delta P_{\mathrm{W}_{i}}(k)+\frac{\partial Q_{\mathrm{W}}^{\min }}{\partial V_{\mathrm{W}}} \Delta V_{\mathrm{W}_{i}}(k), \\
Q_{\mathrm{W}_{i}}^{\max }(k) \approx Q_{\mathrm{W}_{i}}^{\max }\left(t_{0}\right)+\frac{\partial Q_{\mathrm{W}}^{\max }}{\partial P_{\mathrm{W}}} \Delta P_{\mathrm{W}_{i}}(k)+\frac{\partial Q_{\mathrm{W}}^{\max }}{\partial V_{\mathrm{W}}} \Delta V_{\mathrm{W}_{i}}(k),
\end{gathered}
$$

where

$$
\Delta V_{\mathrm{W}_{i}}(k)=\frac{\partial V_{\mathrm{W}_{i}}}{\partial P_{\mathrm{W}}} \Delta P_{\mathrm{W}}+\frac{\partial V_{\mathrm{W}_{i}}}{\partial Q_{\mathrm{W}}} \Delta Q_{\mathrm{W}}+\frac{\partial V_{\mathrm{W}_{i}}}{\partial V_{\mathrm{C}}} \Delta V_{\mathrm{C}}
$$

As mentioned in Section III, the sensitivity coefficients $\partial Q_{\mathrm{W}}^{\min } / \partial V_{\mathrm{W}}, \partial Q_{\mathrm{W}}^{\min } / \partial P_{\mathrm{W}}, \partial Q_{\mathrm{W}}^{\max } / \partial V_{\mathrm{W}}$ and $\partial Q_{\mathrm{W}}^{\max } / \partial P_{\mathrm{W}}$ are calculated based on the linear interpolation approach.

2) VSC Constraints: Since the AC voltage control is adopted by the local controller of WFVSC, the voltage reference at the controlled AC bus is constrained by,

$$
\begin{gathered}
V_{\mathrm{S}}^{\mathrm{min}} \leqslant \Delta V_{\mathrm{S}}^{\mathrm{ref}}(k)+V_{\mathrm{S}}\left(t_{0}\right) \leqslant V_{\mathrm{S}}^{\max },\left\|\Delta V_{\mathrm{S}}^{\mathrm{ref}}\right\|<\Delta V_{\mathrm{S}}^{\mathrm{max}}, \\
k=1,2, \cdots, N_{\mathrm{C}}
\end{gathered}
$$

where $V_{\mathrm{S}}^{\min }$ and $V_{\mathrm{S}}^{\mathrm{max}}$ are the minimum and maximum limits of $V_{\mathrm{S}}$, respectively and $\Delta V_{\mathrm{S}}^{\max }$ is the maximum ramp rate.

3) System Constraints: The OWF is required to track the power reference $P_{\mathrm{WF}}^{\text {ref }}$ from system operators, which can be expressed as,

$$
\sum_{i=1}^{N_{\mathrm{W}}} P_{\mathrm{W}_{i}}^{\mathrm{ref}}=P_{\mathrm{WF}}^{\mathrm{ref}}
$$

The formulated MPC problem (27) (39) can be transformed into a standard quadratic-programming (QP) problem and efficiently solved by commercial QP solvers in milliseconds [37]. More details about the derivations of the mathematical formulation of EVCS-MPC are presented in Appendix A.

\section{CASE STUDY}

A VSC-HVDC connected OWF system with 64 WTGs is used to demonstrate the proposed MPC based EVCS in this section. The structure of the system is presented in Section II. The wind field model considering the turbulences and wake effects for the OWF is generated using the SimWindFarm, a toolbox for dynamic wind farm modeling and simulation [38]. The basic electrical and control system parameters are presented in Appendix B.

To examine the control performance of the MPC-EVCS, several control methods are used to make comparisons: 1) optimal control (OPC) [16]; and 2) the voltage control method based on MPC without considering the effects of active power of WTGs in the optimization (MPC-Q).

\section{A. Scenario A: Normal Operation}

The total simulation time for this scenario is 600 s. Fig. 7 shows the available power and active power reference considering the power ramp rate of the wind farm.

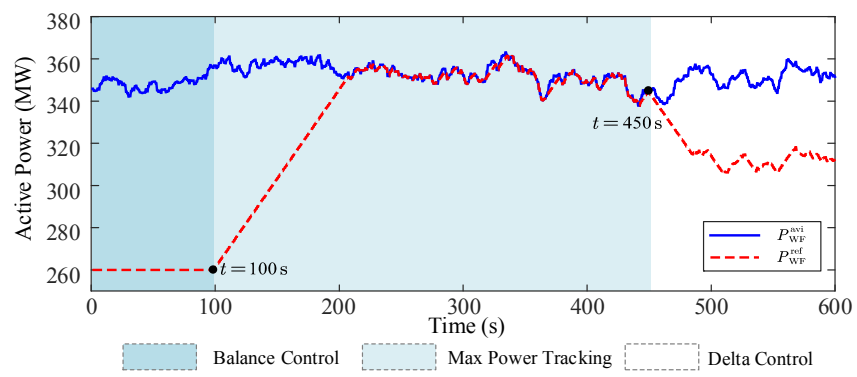

Fig. 7. Active power output of the OWF for Scenario A.

Fig. 8 shows the voltage of bus MV_1 and terminal voltage of WTG_64 (the furthest bus along the feeder). All the three OWF controllers can keep the voltages below their thresholds, and the control systems operate in normal mode. The standard deviations $\sigma\left(V_{\mathrm{MV}_{1}}\right)$ are $0.8512 \%$ for OPC, $0.8387 \%$ for MPC$\mathrm{Q}$ and $0.8367 \%$ for MPC-EVCS. $V_{\mathrm{W}_{64}}$ is closer to the nominal value using MPC-Q or MPC-EVCS than using OPC and is smoother using MPC-EVCS than using MPC-Q owing to the consideration of effects of active power of WTGs on voltage deviations. Thus, the MPC-EVCS shows better performance for voltage regulation. 


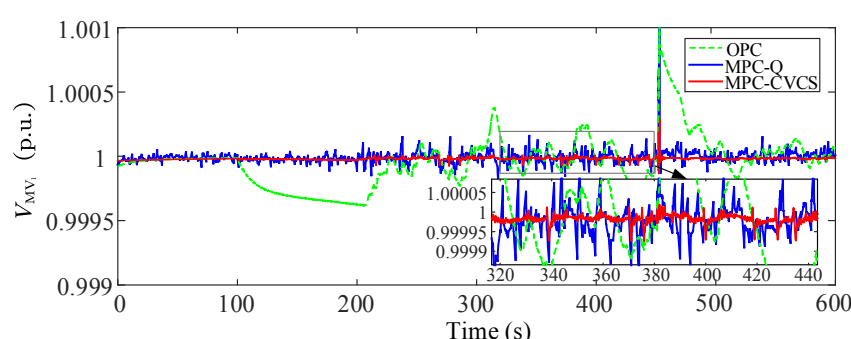

(a)

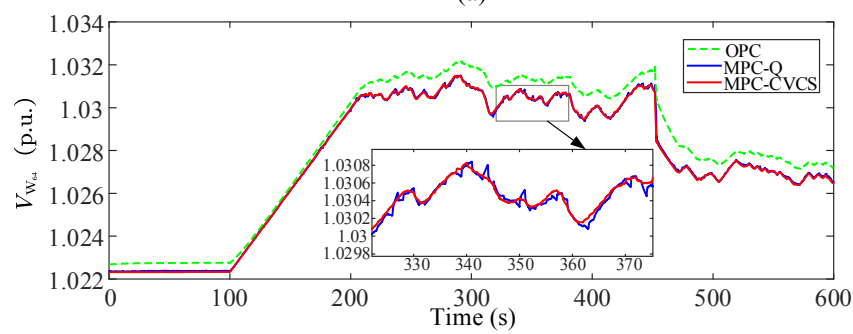

(b)

Fig. 8. Voltages of different buses. (a) Voltage of bus MV_1; (b) terminal voltage of WTG_64.

Fig. 9 shows the power losses of the system. The mean values of power losses within the operating time are 19.5154 MW for OPC, 19.3312 MW for MPC-Q and 19.2187 MW for MPC-EVCS, respectively. It can be seen that the MPC-EVCS shows better performance in power losses reduction.

The reactive power output of WTG_1 is illustrated in Fig. 10. The MPC-Q and MPC-EVCS can both regulate the reactive power of WTGs within small ranges, which enlarges the Var reserves. Compared with the MPC-Q, the MPC-EVCS regulates the reactive power outputs of WTGs more smoothly.

Accordingly, all the three controllers show good control performance in normal operation, whereas comparably, the MPC-EVCS is better than the OPC and MPC-Q.

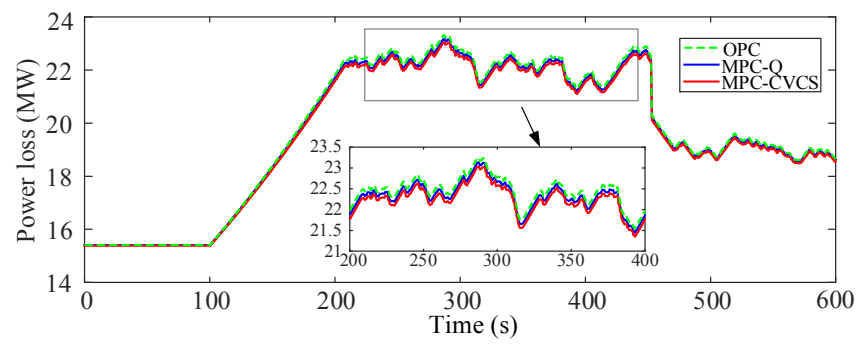

Fig. 9. Power loss of the grid.

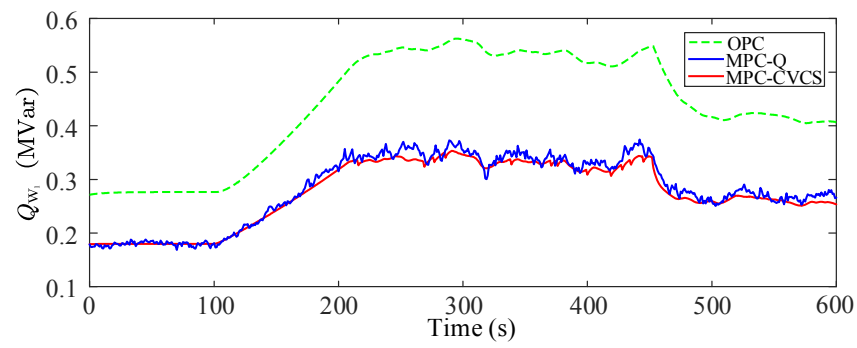

Fig. 10. Reactive power of WTG_1.

\section{B. Scenario B: Voltage Ramp-up Operation}

The voltage ramp-up operation of VSC-HVDC connected OWFs is considered for this scenario. In this scenario, the WFVSC builds up the voltage at the beginning. When the terminal voltages of WTGs reach 0.9 p.u., WTGs are connected to the grid and the controller switches to coordinated control strategy (i.e., the OPC, MPC-Q or MPCEVCS). The total simulation time is $50 \mathrm{~s}$. The simulation results are shown in Figs. 11 13.

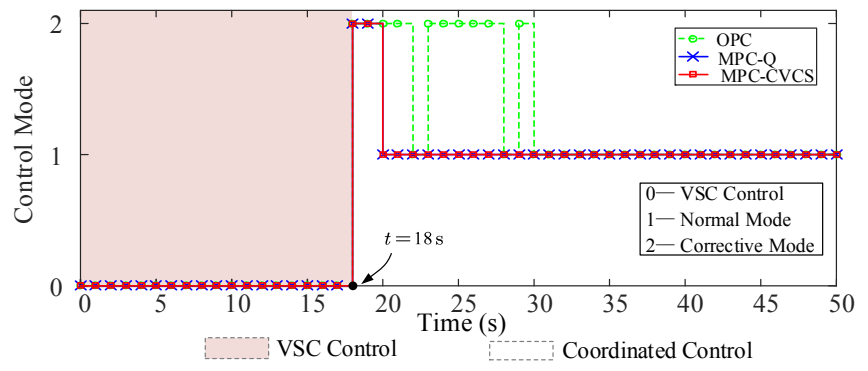

Fig.11. Control mode switching.

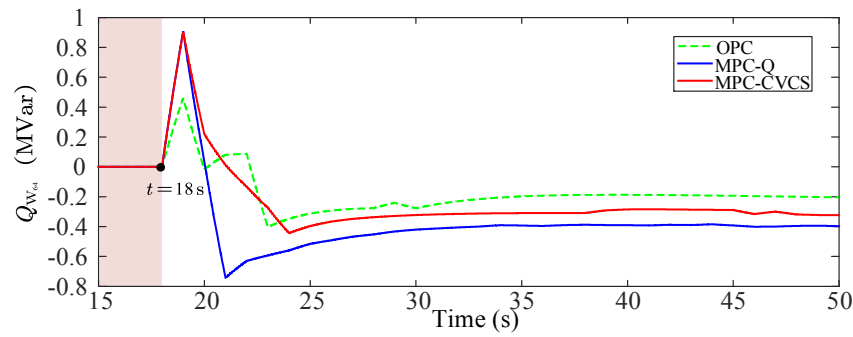

Fig. 12. Reactive power of WTG_64.

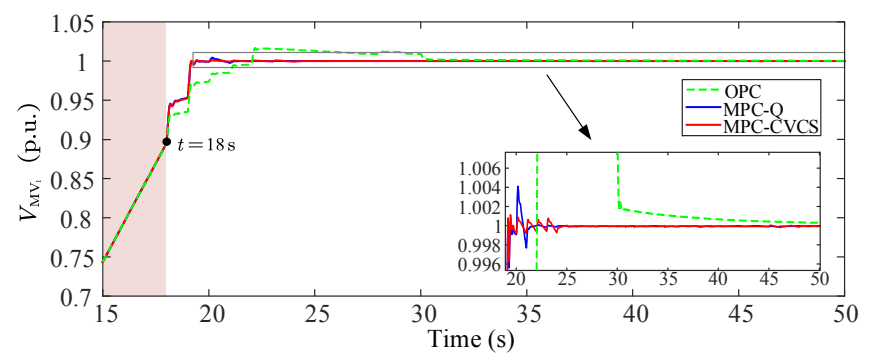

(a)

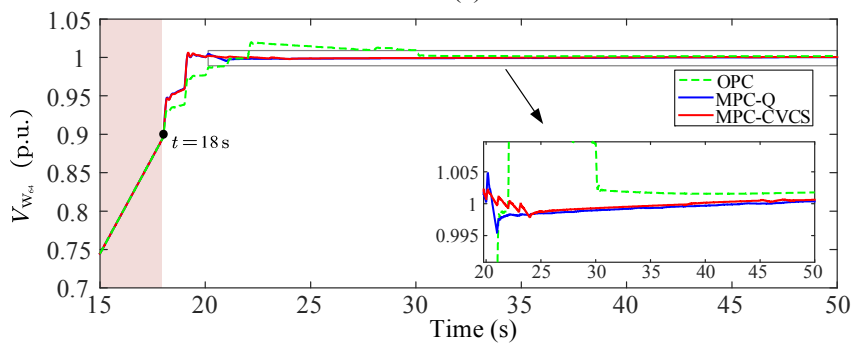

(b)

Fig. 13. Voltages of different buses. (a) Voltage of bus MV_1; (b) terminal voltage of WTG_64.

As can be seen from Fig. 11, all the three control methods switch from the VSC control mode to the corrective mode at $t=18 \mathrm{~s}$. For the MPC-Q and MPC-EVCS, the controllers switch to the normal mode at $t=20 \mathrm{~s}$ and keep stable in the 
remaining period. For the OPC, the controller switches between the corrective mode and normal mode for several times during $t=18 \sim 30 \mathrm{~s}$ and keeps stable after $t=30 \mathrm{~s}$. Fig. 12 shows the reactive power of WTG_64. As can be seen, the WTG generates additional reactive power to support the low voltages of the grid at the beginning of the coordinated control. Fig. 13 shows the voltage of bus MV_1 and terminal voltage of WTG_64. It is shown that the three controllers can well regulate the voltages within feasible ranges in seconds. By comparison, the MPC-Q and MPC-EVCS shows better control performance than the OPC, since the voltages recover within the feasible ranges more quickly for the MPC-Q and MPCEVCS than the OPC.

\section{MPC Solver Performance}

The time consumed by the solver in MPC should be considered in real-time control. In this study, the QP problem was solved using the interior-point method. The estimated available time to execute the control algorithm can be calculated by $T_{\mathrm{C}}-2 T_{\mathrm{d}}=800 \mathrm{~ms}$. The actual mean executing time consumed by the solver in Scenario A is $12.7 \mathrm{~ms}$. Obviously, the actual executing time is much smaller than the available time, satisfying the requirements for real-life application.

\section{CONCLUSIONS}

In this paper, a MPC based EVCS is developed to optimize voltage control within VSC-HVDC connected OWFs, which can regulate the voltages while taking into account economical operation of the OWFs. The predictive model of WFVSC with a typical cascaded control structure is derived in details. An analytical sensitivity coefficient calculation method is adopted to improve computational efficiency. In the MPC-EVCS, two control modes are designed for different operating conditions. The case studies show that all the three different optimization control methods OPC, MPC-Q and MPC-EVCS show good control performance in different scenarios. In comparison, the overall performance of the MPC-EVCS is better than the MPC-Q and OPC. Of course, more work is required for further improvement. A nonlinear model of the system will be investigated to more accurately capture the complex dynamics of the systems and improve the control performance in the future work.

\section{APPENDIX A}

\section{MATHEMATICAL FORMULATION OF MPC}

To derive the mathematical formulation of the optimization problem in the MPC-EVCS, firstly transform the state variables, control variables and output variables into unified forms:

$$
\begin{aligned}
& \Delta U=\left[\Delta u(1), \Delta u(2), \ldots, \Delta u\left(N_{\mathrm{C}}\right)\right]^{\mathrm{T}}, \\
& \Delta X=\left[\Delta x(1), \Delta x(2), \ldots, \Delta x\left(N_{\mathrm{P}}\right)\right]^{\mathrm{T}}, \\
& \Delta Y=\left[\Delta y(1), \Delta y(2), \ldots, \Delta y\left(N_{\mathrm{P}}\right)\right]^{\mathrm{T}} .
\end{aligned}
$$

For the sake of clarity, the derivations are divided into four steps as follows.

\section{Step I: Represent $\Delta X$ and $\Delta Y$ by $\Delta U$.}

According to (26), it can be obtained that

$$
\begin{aligned}
& \Delta X=W_{X U} \Delta U \\
& \Delta Y=W_{Y X} \Delta X
\end{aligned}
$$

where

$$
\begin{aligned}
& W_{X U}=\left[\begin{array}{cccc}
W_{11} & & & \\
W_{21} & W_{22} & & \\
\vdots & \vdots & \ddots & \\
W_{N_{\mathrm{C}}, 1} & W_{N_{\mathrm{C}}, 2} & \cdots & W_{N_{\mathrm{C}}, N_{\mathrm{C}}}
\end{array}\right], W_{i j}=\left[\begin{array}{c}
\mathcal{W}_{i j}^{1} \\
\mathcal{W}_{i j}^{2} \\
\vdots \\
\mathcal{W}_{i j}^{N_{\mathrm{S}}}
\end{array}\right], \\
& W_{Y X}=I_{N_{\mathrm{P}}} \otimes C=\left[\begin{array}{cccc}
C & & & \\
& C & & \\
& & \ddots & \\
& & & C
\end{array}\right] .
\end{aligned}
$$

The elements of the matrix $W_{X U}$ are calculated using the following recursive method:

For $W_{i j}(i>j)$ :

$$
\mathcal{W}_{i j}^{k}=G^{k} \mathcal{W}_{i-1, j}^{N_{\mathrm{S}}}, k=1,2, \ldots, N_{\mathrm{S}} .
$$

For $W_{i j}(i=j)$ :

$\mathcal{W}_{i j}^{k}=\left(I+G+G^{2}+\cdots+G^{k-1}\right) H, k=1,2, \ldots, N_{\mathrm{S}}$.

\section{Step II: Represent the predictive values by $\Delta U$.}

Based on (29), $\Delta V_{\mathrm{MV}}^{\mathrm{pre}}$ can be transformed into a compact form

$$
\Delta V_{\mathrm{MV}}^{\mathrm{pre}}=\left(I_{N_{\mathrm{P}}} \otimes S_{\mathrm{MV}}\right) \Delta Y+\mathbf{1}_{N_{\mathrm{P}}} \otimes\left(V_{\mathrm{MV}}\left(t_{0}\right)-V_{\mathrm{MV}}^{\mathrm{ref}}\right),
$$

where

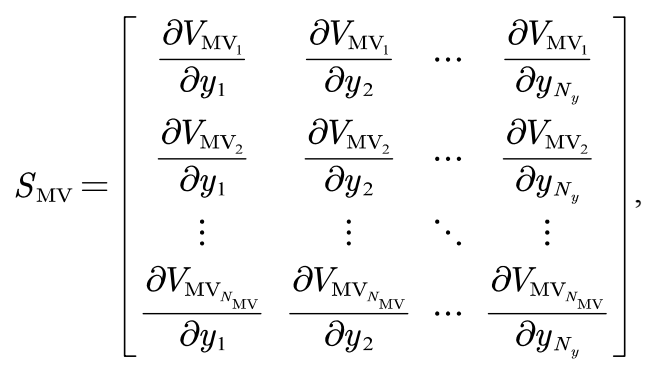

which can be directly obtained using (4) (7).

Similarly, according to (36), $\Delta V_{\mathrm{W}}^{\mathrm{pre}}$ can be written as

$$
\Delta V_{\mathrm{W}}^{\mathrm{pre}}=\left(I_{N_{\mathrm{P}}} \otimes S_{\mathrm{WT}}\right) \Delta Y+\mathbf{1}_{N_{\mathrm{P}}} \otimes\left(V_{\mathrm{W}}\left(t_{0}\right)-V_{\mathrm{W}}^{\mathrm{ref}}\right)
$$

where 


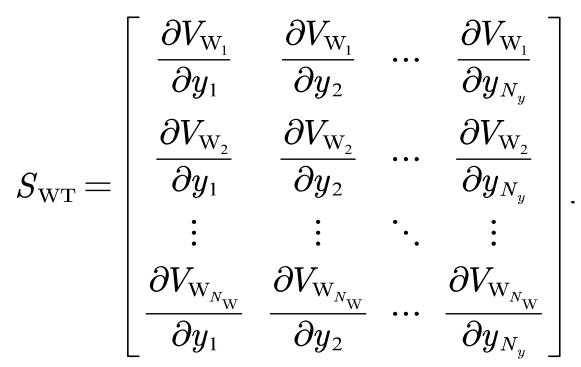

Similarly, $S_{\mathrm{WT}}$ can be directly calculated using (4) -(7).

According to (31), $P_{\text {LOSS }}^{\text {pre }}$ can be represented by,

$$
P_{\mathrm{LOSS}}^{\mathrm{pre}}=\left(I_{N_{\mathrm{P}}} \otimes S_{\mathrm{PL}}\right) \Delta Y+\mathbf{1}_{N_{\mathrm{P}}} \otimes P_{\mathrm{LOSS}}\left(t_{0}\right)
$$

where

$$
S_{\mathrm{PL}}=\left[\frac{\partial P_{\mathrm{LOSS}}}{y_{1}}, \frac{\partial P_{\mathrm{LOSS}}}{\partial y_{2}}, \ldots, \frac{\partial P_{\mathrm{LOSS}}}{\partial y_{N_{y}}}\right] .
$$

The calculation of $S_{\mathrm{PL}}$ is presented as follows.

From (14), one can obtain,

$$
\Delta P_{\mathrm{LOSS}}=\Delta P_{\mathrm{Grid}}^{\mathrm{LOSS}}+\Delta P_{\mathrm{WFVSC}}^{\mathrm{LOSS}}+\Delta\left(\sum_{i=1}^{N_{\mathrm{W}}} P_{\mathrm{GSC}_{i}}^{\mathrm{LOSS}}\right),
$$

where

$$
\begin{aligned}
& \Delta P_{\mathrm{Grid}}^{\mathrm{LOSS}}=\frac{\partial P_{\mathrm{Grid}}^{\mathrm{LOSS}}}{\partial P_{\mathrm{W}}} \Delta P_{\mathrm{W}}+\frac{\partial P_{\mathrm{Grid}}^{\mathrm{LOSS}}}{\partial Q_{\mathrm{W}}} \Delta Q_{\mathrm{W}}+\frac{\partial P_{\mathrm{Grid}}^{\mathrm{LOSS}}}{\partial V_{\mathrm{C}}} \Delta V_{\mathrm{C}}, \\
& \Delta P_{\mathrm{WFVSC}}^{\mathrm{LOSS}}=\frac{\partial P_{\mathrm{WFVSC}}^{\mathrm{LOSS}}}{\partial P_{\mathrm{WFVSC}}} \Delta P_{\mathrm{WFVSC}}+\frac{\partial P_{\mathrm{Grid}}^{\mathrm{LOSS}}}{\partial Q_{\mathrm{WFVSC}}} \Delta Q_{\mathrm{WFVSC}} \\
& \approx \frac{\partial P_{\mathrm{WFVSC}}^{\mathrm{LOSS}}}{\partial P_{\mathrm{WFVSC}}}\left(\mathbf{1}_{N_{\mathrm{W}}}^{T} \Delta P_{\mathrm{W}}\right)+\frac{\partial P_{\mathrm{WFVSC}}^{\mathrm{LOSS}}}{\partial Q_{\mathrm{WFVSC}}}\left(\mathbf{1}_{N_{\mathrm{W}}}^{\mathrm{T}} \Delta Q_{\mathrm{W}}\right), \\
& \Delta\left(\sum_{i=1}^{N_{\mathrm{W}}} P_{\mathrm{GSC}_{i}}^{\mathrm{LOSS}}\right)=\frac{\partial P_{\mathrm{GSC}}^{\mathrm{LOSS}}}{\partial P_{\mathrm{GSC}}} \Delta P_{\mathrm{W}}+\frac{\partial P_{\mathrm{GSC}}^{\mathrm{LOSS}}}{\partial Q_{\mathrm{GSC}}} \Delta Q_{\mathrm{W}}
\end{aligned}
$$

Then, $S_{\mathrm{PL}}$ can be represented as,

$$
\begin{array}{r}
S_{\mathrm{PL}}=\left[\frac{\partial P_{\mathrm{Grid}}^{\mathrm{LOSS}}}{\partial V_{\mathrm{C}}}, \frac{\partial P_{\mathrm{Grid}}^{\mathrm{LOSS}}}{\partial P_{\mathrm{W}}}+\frac{\partial P_{\mathrm{WFVSC}}^{\mathrm{LOSS}}}{\partial P_{\mathrm{WFVSC}}} \cdot \mathbf{1}_{N_{\mathrm{W}}}^{\mathrm{T}}+\frac{\partial P_{\mathrm{GSC}}^{\mathrm{LOSS}}}{\partial P_{\mathrm{GSC}}}\right. \\
\left.\frac{\partial P_{\mathrm{Grid}}^{\mathrm{LOSS}}}{\partial Q_{\mathrm{W}}}+\frac{\partial P_{\mathrm{WFVSC}}^{\mathrm{LOSS}}}{\partial Q_{\mathrm{WFVSC}}} \cdot \mathbf{1}_{N_{\mathrm{w}}}^{\mathrm{T}}+\frac{\partial Q_{\mathrm{GSC}}^{\mathrm{LOSS}}}{\partial Q_{\mathrm{GSC}}}\right]
\end{array}
$$

According to (32), $\Delta P_{\mathrm{W}}^{\mathrm{PD}}$ can be represented by,

$$
\Delta P_{\mathrm{W}}^{\mathrm{PD}}=\left(I_{N_{\mathrm{P}}} \otimes S_{\mathrm{AP}}\right) \Delta Y+\mathbf{1}_{N_{\mathrm{P}}} \otimes\left(P_{\mathrm{W}}\left(t_{0}\right)-P_{\mathrm{W}}^{\mathrm{PD}}{ }^{\mathrm{ref}}\right)
$$

where

$$
\begin{aligned}
S_{\mathrm{AP}} & =\left[\begin{array}{c|cccc|cccc}
0 & 1 & 0 & \cdots & 0 & 0 & 0 & \cdots & 0 \\
0 & 0 & 1 & \cdots & 0 & 0 & 0 & \cdots & 0 \\
\vdots & \vdots & \vdots & \ddots & \vdots & \vdots & \vdots & \ddots & \vdots \\
0 & 0 & 0 & \cdots & 1 & 0 & 0 & \cdots & 0
\end{array}\right] \\
& =\left[\begin{array}{lll}
\mathbf{0}_{N_{\mathrm{W}} \times 1} & I_{N_{\mathrm{W}}} & \mathbf{0}_{N_{\mathrm{W}} \times N_{\mathrm{W}}}
\end{array}\right]
\end{aligned}
$$

Then, substituting (41)-(42) into (44)- (46) and (49), the predictive values can be explicitly represented by $\Delta U$,

$$
\begin{gathered}
\Delta V_{\mathrm{MV}}^{\mathrm{pre}}=M_{\mathrm{MV}} \Delta U+E_{\mathrm{MV}}, \\
\Delta V_{\mathrm{W}}^{\mathrm{pre}}=M_{\mathrm{WT}} \Delta U+E_{\mathrm{WT}}, \\
P_{\mathrm{LOSS}}^{\mathrm{pre}}=M_{\mathrm{PL}} \Delta U+E_{\mathrm{PL}}, \\
\Delta P_{\mathrm{W}}^{\mathrm{PD}}=M_{\mathrm{AP}} \Delta U+E_{\mathrm{AP}},
\end{gathered}
$$

where

$$
\begin{aligned}
& M_{\mathrm{MV}}=I_{N_{\mathrm{P}}} \otimes S_{\mathrm{MV}} W_{Y X} W_{X U}, E_{\mathrm{MV}}=\mathbf{1}_{N_{\mathrm{P}}} \otimes\left(V_{\mathrm{MV}}\left(t_{0}\right)-V_{\mathrm{MV}}^{\mathrm{ref}}\right), \\
& M_{\mathrm{WT}}=I_{N_{\mathrm{P}}} \otimes S_{\mathrm{WT}} W_{Y X} W_{X U}, E_{\mathrm{WT}}=\mathbf{1}_{N_{\mathrm{P}}} \otimes\left(V_{\mathrm{W}}\left(t_{0}\right)-V_{\mathrm{W}}^{\mathrm{ref}}\right), \\
& M_{\mathrm{PL}}=I_{N_{\mathrm{P}}} \otimes S_{\mathrm{PL}} W_{Y X} W_{X U}, E_{\mathrm{PL}}=\mathbf{1}_{N_{\mathrm{P}}} \otimes P_{\mathrm{LOSS}}\left(t_{0}\right), \\
& M_{\mathrm{AP}}=I_{N_{\mathrm{P}}} \otimes S_{\mathrm{AP}} W_{Y X} W_{X U}, E_{\mathrm{AP}}=\mathbf{1}_{N_{\mathrm{P}}} \otimes\left(P_{\mathrm{W}}\left(t_{0}\right)-P_{\mathrm{W}}^{\mathrm{PD} \_ \text {ref }}\right) .
\end{aligned}
$$

Step III: Represent the constraints by $\Delta U$.

The constraints (36) and (37) can be written compactly as,

$$
\begin{aligned}
& 0 \leqslant\left(I_{N_{\mathrm{P}}} \otimes S_{\mathrm{AP}}\right) \Delta Y+\mathbf{1}_{N_{\mathrm{P}}} \otimes P_{\mathrm{W}}\left(t_{0}\right) \leqslant \mathbf{1}_{N_{\mathrm{P}}} \otimes P_{\mathrm{W}}^{\mathrm{av}}, \\
& Q_{\mathrm{W}}^{\min } \leqslant\left(I_{N_{\mathrm{P}}} \otimes S_{R \mathrm{P}}\right) \Delta Y+\mathbf{1}_{N_{\mathrm{P}}} \otimes Q_{\mathrm{W}}\left(t_{0}\right) \leqslant Q_{\mathrm{W}}^{\max } .
\end{aligned}
$$

where

$$
\begin{aligned}
& S_{\mathrm{RP}}=\left[\begin{array}{c|cccc|cccc}
0 & 0 & 0 & \cdots & 0 & 1 & 0 & \cdots & 0 \\
0 & 0 & 0 & \cdots & 0 & 0 & 1 & \cdots & 0 \\
\vdots & \vdots & \vdots & \ddots & \vdots & \vdots & \vdots & \ddots & \vdots \\
0 & 0 & 0 & \cdots & 0 & 0 & 0 & \cdots & 1
\end{array}\right] \\
& =\left[\begin{array}{lll}
\mathbf{0}_{N_{\mathrm{W}} \times 1} & \mathbf{0}_{N_{\mathrm{W}} \times N_{\mathrm{W}}} & I_{N_{\mathrm{W}}}
\end{array}\right] \\
& Q_{\mathrm{W}}^{\min }=I_{N_{\mathrm{P}}} \otimes\left(S_{Q \min }^{P} S_{\mathrm{AP}}+S_{Q \min }^{V} S_{\mathrm{MV}}\right) \Delta Y+\mathbf{1}_{N_{\mathrm{P}}} \otimes Q_{\mathrm{W}}^{\min }\left(t_{0}\right) \\
& Q_{\mathrm{W}}^{\max }=I_{N_{\mathrm{P}}} \otimes\left(S_{Q \max }^{P} S_{\mathrm{AP}}+S_{Q \max }^{V} S_{\mathrm{MV}}\right) \Delta Y+\mathbf{1}_{N_{\mathrm{P}}} \otimes Q_{\mathrm{W}}^{\max }\left(t_{0}\right) \\
& S_{Q \min }^{P}=\operatorname{diag}\left(\frac{\partial Q_{W_{1}}^{\min }}{\partial P_{\mathrm{W}_{1}}}, \frac{\partial Q_{W_{2}}^{\min }}{\partial P_{\mathrm{W}_{2}}}, \ldots, \frac{\partial Q_{\mathrm{W}_{N_{\mathrm{W}}}}^{\min }}{\partial P_{\mathrm{W}_{N_{\mathrm{W}}}}}\right), \\
& S_{Q \min }^{V}=\operatorname{diag}\left(\frac{\partial Q_{W_{1}}^{\min }}{\partial V_{\mathrm{W}_{1}}}, \frac{\partial Q_{W_{2}}^{\min }}{\partial V_{\mathrm{W}_{2}}}, \ldots, \frac{\partial Q_{\mathrm{W}_{N_{\mathrm{W}}}}^{\min }}{\partial V_{\mathrm{W}_{N_{\mathrm{W}}}}}\right) \text {, } \\
& S_{Q \max }^{P}=\operatorname{diag}\left(\frac{\partial Q_{W_{1}}^{\max }}{\partial P_{\mathrm{W}_{1}}}, \frac{\partial Q_{W_{2}}^{\max }}{\partial P_{\mathrm{W}_{2}}}, \ldots, \frac{\partial Q_{\mathrm{W}_{N_{\mathrm{W}}}}^{\max }}{\partial P_{\mathrm{W}_{N_{\mathrm{W}}}}}\right) \text {, } \\
& S_{Q \max }^{V}=\operatorname{diag}\left(\frac{\partial Q_{W_{1}}^{\max }}{\partial V_{\mathrm{W}_{1}}}, \frac{\partial Q_{W_{2}}^{\max }}{\partial V_{\mathrm{W}_{2}}}, \ldots, \frac{\partial Q_{\mathrm{W}_{N_{\mathrm{W}}}}^{\max }}{\partial V_{\mathrm{W}_{N_{\mathrm{W}}}}}\right) .
\end{aligned}
$$

Then, substituting (41) -(42) into (51), (51) can be arranged to

$$
\begin{gathered}
\Delta U_{P}^{\min } \leqslant F_{P} \Delta U \leqslant \Delta U_{P}^{\max }, \\
\Delta U_{Q}^{\min } \leqslant F_{Q \min } \Delta U, F_{Q \max } \Delta U \leqslant \Delta U_{Q}^{\max },
\end{gathered}
$$




$$
\begin{aligned}
& F_{P}=\left(I_{N_{\mathrm{P}}} \otimes S_{\mathrm{AP}}\right) W_{Y X} W_{X U}, \\
& \Delta U_{P}^{\min }=-\mathbf{1}_{N_{\mathrm{P}}} \otimes P_{\mathrm{W}}\left(t_{0}\right), \\
& \Delta U_{P}^{\max }= \mathbf{1}_{N_{\mathrm{P}}} \otimes P_{\mathrm{W}}^{\mathrm{av}}-\mathbf{1}_{N_{\mathrm{P}}} \otimes P_{\mathrm{W}}\left(t_{0}\right), \\
& F_{Q \min }=\left(I_{N_{\mathrm{P}}} \otimes S_{\mathrm{RP}}\right) W_{Y X} W_{X U} \\
&-I_{N_{\mathrm{P}}} \otimes\left(S_{Q \min }^{P} S_{\mathrm{AP}}+S_{Q \min }^{V} S_{\mathrm{WT}}\right) W_{Y X} W_{X U}, \\
& F_{Q \max }=\left(I_{N_{\mathrm{P}}} \otimes S_{\mathrm{RP}}\right) W_{Y X} W_{X U} \\
&-I_{N_{\mathrm{P}}} \otimes\left(S_{Q \max }^{P} S_{\mathrm{AP}}+S_{Q \max }^{V} S_{\mathrm{WT}}\right) W_{Y X} W_{X U}, \\
& \Delta U_{Q}^{\min }= \mathbf{1}_{N_{\mathrm{P}}} \otimes Q_{\mathrm{W}}^{\min }\left(t_{0}\right)-\mathbf{1}_{N_{\mathrm{P}}} \otimes Q_{\mathrm{W}}\left(t_{0}\right), \\
& \Delta U_{Q}^{\max }= \mathbf{1}_{N_{\mathrm{P}}} \otimes Q_{\mathrm{W}}^{\max }\left(t_{0}\right)-\mathbf{1}_{N_{\mathrm{P}}} \otimes Q_{\mathrm{W}}\left(t_{0}\right) .
\end{aligned}
$$

The constraints (38) can be written compactly as,

$\mathbf{1}_{N_{\mathrm{C}}} \otimes V_{\mathrm{S}}^{\min } \leqslant\left(I_{N_{\mathrm{C}}} \otimes S_{V U}\right) \Delta U+\mathbf{1}_{N_{\mathrm{C}}} \otimes V_{S}\left(t_{0}\right) \leqslant \mathbf{1}_{N_{\mathrm{C}}} \otimes V_{\mathrm{S}}^{\max }$,

$-\mathbf{1}_{N_{\mathrm{C}}} \otimes \Delta V_{\mathrm{S}}^{\max } \leqslant\left(I_{N_{\mathrm{C}}} \otimes S_{V U}\right) \Delta U \leqslant \mathbf{1}_{N_{\mathrm{C}}} \otimes \Delta V_{\mathrm{S}}^{\max }$,

where $S_{V U}=\underbrace{[1,0,0, \ldots, 0]}_{N_{u}}$.

Similarly, (53) can be simplified to

$$
\begin{aligned}
& \Delta U_{V}^{\min } \leqslant F_{V} \Delta U \leqslant \Delta U_{V}^{\max }, \\
& \Delta U_{\Delta V}^{\min } \leqslant F_{\Delta V} \Delta U \leqslant \Delta U_{\Delta V}^{\max },
\end{aligned}
$$

where

$$
\begin{aligned}
& F_{V}=F_{\Delta V}=I_{N_{\mathrm{C}}} \otimes S_{V U}, \\
& \Delta U_{V}^{\min }=\mathbf{1}_{N_{\mathrm{C}}} \otimes V_{\mathrm{S}}^{\min }-\mathbf{1}_{N_{\mathrm{C}}} \otimes V_{\mathrm{S}}\left(t_{0}\right), \\
& \Delta U_{V}^{\max }=\mathbf{1}_{N_{\mathrm{C}}} \otimes V_{\mathrm{S}}^{\max }-\mathbf{1}_{N_{\mathrm{C}}} \otimes V_{\mathrm{S}}\left(t_{0}\right), \\
& \Delta U_{\Delta V}^{\min }=-\mathbf{1}_{N_{\mathrm{C}}} \otimes \Delta V_{\mathrm{S}}^{\max }, \\
& \Delta U_{\Delta V}^{\max }=\mathbf{1}_{N_{\mathrm{C}}} \otimes \Delta V_{\mathrm{S}}^{\max } .
\end{aligned}
$$

According to (40), the constraint of active power output of the wind farm can be compactly represented as,

$$
F_{E} \Delta U=\Delta U_{E}
$$

where

$$
\begin{aligned}
& F_{E}=\mathbf{1}_{N_{\mathrm{C}}} \otimes\left[\begin{array}{c|cccc|cccc}
0 & 1 & 1 & \cdots & 1 & 0 & 0 & \cdots & 0 \\
0 & 1 & 1 & \cdots & 1 & 0 & 0 & \cdots & 0 \\
\vdots & \vdots & \vdots & \ddots & \vdots & \vdots & \vdots & \ddots & \vdots \\
0 & 1 & 1 & \cdots & 1 & 0 & 0 & \cdots & 0
\end{array}\right] \\
& =\mathbf{1}_{N_{\mathrm{C}}} \otimes\left[\begin{array}{lll}
\mathbf{0}_{N_{\mathrm{W}} \times 1} & \mathbf{1}_{N_{\mathrm{W}}}^{\mathrm{T}} \otimes \mathbf{1}_{N_{\mathrm{W}}} & \mathbf{0}_{N_{\mathrm{W}} \times N_{\mathrm{W}}}
\end{array}\right] \\
& \Delta U_{E}=\mathbf{1}_{N_{\mathrm{C}}} \otimes\left(P_{\mathrm{WF}}^{\mathrm{ref}}-\mathbf{1}_{N_{\mathrm{W}}}^{\mathrm{T}} P_{\mathrm{W}}\left(t_{0}\right)\right)
\end{aligned}
$$

\section{Step IV: Mathematical model of MPC}

The MPC can be formulated as optimization problems which are as follows:

1) For normal mode, (33) can be rewritten as an explicit form of $\Delta U$ :

$$
\begin{aligned}
\min _{\Delta U} J & =\left\|M_{\mathrm{MV}} \Delta U+E_{\mathrm{MV}}\right\|_{\Lambda_{\mathrm{V}}}^{2} \\
& +\left\|M_{\mathrm{PL}} \Delta U+E_{\mathrm{PL}}\right\|_{\Lambda_{\mathrm{L}}}^{2}+\left\|M_{\mathrm{AP}} \Delta U+E_{\mathrm{AP}}\right\|_{\Lambda_{\mathrm{P}}}^{2}
\end{aligned}
$$

subject to

$$
\text { (52a),(52 b), (54a),(54b),(55) }
$$

where $\Lambda_{\mathrm{V}}=\lambda_{\mathrm{V}} I_{N_{\mathrm{MV}} N_{\mathrm{P}}}, \Lambda_{\mathrm{L}}=\lambda_{\mathrm{L}} I_{N_{\mathrm{P}}}, \Lambda_{\mathrm{P}}=\lambda_{\mathrm{P}} I_{N_{\mathrm{W}} N_{\mathrm{P}}}$.

2) For corrective mode, (34) can be rewritten as an explicit form of $\Delta U$ :

$$
\begin{aligned}
& \underset{\Delta U}{\min } J=\left\|M_{\mathrm{WT}} \Delta U+E_{\mathrm{WT}}\right\|_{\Lambda_{\mathrm{W}}}^{2}+\left\|M_{\mathrm{MV}} \Delta U+E_{\mathrm{MV}}\right\|_{\Lambda_{\mathrm{MV}}}^{2} \\
& \text { subject to } \\
& \qquad(52 \mathrm{a}),(52 \mathrm{~b}),(54 \mathrm{a}),(54 \mathrm{~b}),(55)
\end{aligned}
$$

where $\Lambda_{\mathrm{W}}=\lambda_{\mathrm{W}} I_{N_{\mathrm{P}}}, \Lambda_{\mathrm{MV}}=\lambda_{\mathrm{MV}} I_{N_{\mathrm{P}}}$.

As such, the mathematical models of MPC are obtained. Obviously, they can be converted into standard QP problems and can be efficiently solved by the QP solvers.

\section{APPENDIX B}

\section{SYSTEM PARAMETERS}

The basic electrical and control system parameters are listed in Tables I III.

TABLE I

ELECTRICAL SYSTEM PARAMETERS

\begin{tabular}{c|c}
\hline \hline 33kV Cable & $R=0.0975 \Omega / \mathrm{km}, L=0.38 \mathrm{mH} / \mathrm{km}, C=0.24 \mu \mathrm{F} / \mathrm{km}$ \\
$150 \mathrm{kV}$ Cable & $R=0.0326 \Omega / \mathrm{km}, L=0.42 \mathrm{mH} / \mathrm{km}, C=0.15 \mu \mathrm{F} / \mathrm{km}$ \\
0.9/33kV Transformer & $S_{\mathrm{n}}=6.25 \mathrm{MVA}, R=0.008$ p.u., $X=0.06$ p.u. \\
$33 / 150 \mathrm{kV}$ Transformer & $S_{\mathrm{n}}=100 \mathrm{MVA}, R=0.005$ p.u., $X=0.12$ p.u. \\
150/170kV Transformer & $S_{\mathrm{n}}=400 \mathrm{MVA}, R=0.006$ p.u., $X=0.14$ p.u. \\
HVDC Converter & $\mathrm{S}_{\mathrm{n}}=400 \mathrm{MVA}$ \\
GSC & $\mathrm{S}_{\mathrm{n}}=6.25 \mathrm{MVA}$ \\
$R_{\mathrm{C}}+\mathrm{j} X_{\mathrm{C}}$. & $\odot .0178+\mathrm{j} \odot .196 \mathrm{p} . \mathrm{u}$. \\
$\mathrm{C}_{\mathrm{f}}$ & $10 \mu \mathrm{F}$ \\
\hline \hline
\end{tabular}

TABLE II

TYPICAL CONVERTER LOSS PARAMETERS [21]

\begin{tabular}{cccc}
\hline \hline System & $a$ & $b$ & $c$ \\
\hline GSC & 0.0005 & 0.0097 & 0.0048 \\
HVDC Converter & 0.0083 & 0.0030 & 0.0032 \\
\hline \hline
\end{tabular}

TABLE III

CONTROL SYSTEM PARAMETERS

\begin{tabular}{c|c|c|c}
\hline \hline $\mathrm{T}_{\mathrm{C}}$ & $1 \mathrm{~s}$ & $\lambda_{\mathrm{V}}$ & 0.8 \\
$\mathrm{~T}_{\mathrm{P}}$ & $5 \mathrm{~s}$ & $\lambda_{\mathrm{L}}$ & 0.1 \\
$\mathrm{~T}_{\mathrm{d}}$ & $100 \mathrm{~ms}$ & $\lambda_{\mathrm{P}}$ & $0.1 / 64$
\end{tabular}




\begin{tabular}{c|c|c|c}
$\mathrm{T}_{\mathrm{inr}}$ & $5 \mathrm{~ms}$ & $\mathrm{~V}_{\mathrm{W}}^{\text {th }}$ & 0.05 p.u. \\
$\Delta \mathrm{T}_{\mathrm{P}}$ & $50 \mathrm{~ms}$ & $\mathrm{~V}_{\mathrm{MV}}^{\mathrm{th}}$ & 0.01 p.u. \\
\hline \hline
\end{tabular}

\section{REFERENCES}

[1] Wind energy scenarios for 2030, European Wind Energy Association [Online].Available:https://windeurope.org/fileadmin/files/library/publica tions/reports/EWEA-Wind-energy-scenarios-2030.pdf.

[2] P. Breseti, W. L. Kling, R. L. Hendriks and R. Vailati, "HVDC connection of offshore wind farms to the transmission system," IEEE Trans. Energy Convers., vol. 22, no. 1, pp. 37-43, Mar. 2007.

[3] L. Xu, L. Fan, and Z. Miao, "DC impedance-model-based resonance analysis of a VSC-HVDC System," IEEE Trans. Power Del., vol. 30, no. 3, pp. 1221-1230, Jun. 2015 .

[4] D. Zheng, A. T. Eseye, J. Zhang, and H. Li. "Short-term wind power forecasting using a double-stage hierarchical ANFIS approach for energy management in microgrids," Protection and Control of Modern Power Systems, vol.2, no. 1, pp. 1-10, 2017.

[5] M. Mohseni and S. M. Islam, "Review of international grid codes for wind power integration: Diversity, technology and a case for global standard," Renewable Sustain. Energy Rev., vol. 16, pp. 3876-3890, Aug. 2012.

[6] European Commission,"COMMISSION REGULATION (EU) 2016/631 of 14 April 2016 establishing a network code on requirements for grid connection of generators,"Off. J. Eur. Union., pp. 10-54, 2016. [Online]. Available:https://www.sprk.gov.lv/uploads/doc/2016631EN.pdf

[7] European Commission, "COMMISSION REGULATION (EU) 2016/1447 of 26 August 2016 establishing a network code on requirements for grid connection of high voltage direct current systems and direct current-connected power park modules," Off. J. Eur. Union. pp. 1-65, 2016. [Online]. Available:https://www.entsoe.eu/Documents/ Network\%20codes\%20documents/NC\%20HVDC/EC\%20Regulation $\% 2$ 0\%28EU\%29\%202016\%201447\%20HVDC\%20network\%20code.pdf

[8] B. R. Karthikeya and R. J. Schutt, "Overview of wind park control strategies," IEEE Trans. on Sustain. Energy, vol. 5, no. 2, pp. 416-422, Apr. 2014.

[9] X. Guan and G. M. van der Molen, Control strategy review and specification (Part 1), 2009 [Online]. Available: http://ict-aeolus.eu/pub/ ISC 300409 deliverable_D3-1_0001(1)_PU.pdf.

[10] T. Kaneko, T. Senjyu, A. Yona, M. Datta, T. Funabashi, and C.-H. Kim "Output power coordination control for wind farm in small power system," in Proc. 14th Int. Conf. Intel. Syst. Appl. Power Syst. (ISAP 2007), Nov., pp. 51-56.

[11] A. D. Hansen, P. E. Sørensen, F. Iov, and F. Blaabjerg, "Centralised power control of wind farm with doubly fed induction generators," Renewable Energy, vol. 31, no. 7, pp. 935-951, 2006.

[12] J. Fortmann, M. Wilch, F. W. Koch, and I. Erlich, "A novel centralised wind farm controller utilising voltage control capability of wind turbines," in Proc. PSCC Power Syst. Comput. Conf., 2008, pp. 914 919.

[13] H. Zhao, Q. Wu, Q. Guo, H. Sun, S. Huang, and Y. Xue, "Coordinated voltage control of a wind farm based on model predictive control", IEEE Trans. Sustain. Energy, vol. 7, no. 4, pp. 1440-1451, Oct. 2016.

[14] P. E. Sørensen, A. D. Hansen, F. Iov, F. Blaabjerg, and M. H. Donovan, "Wind farm models and control strategies," Risø Nat. Lab., Denmark, Roskilde, Tech. Rep. Risø-4-1464, Aug. 2005.

[15] J. Martínez, P. C. Kjær, P. Rodriguez, and R. Teodorescu, "Comparison of two voltage control strategies for a wind power plant," in Proc. IEEE/PES Power Syst. Conf. Expo. (PSCE), 2011, pp. 1-9.

[16] Q. Guo, H. Sun, B. Wang, B. Zhang, W. Wu and L. Tang, "Hierarchical automatic voltage control for integration of large-scale wind power: Design and implementation," Electr. Power Syst. Res., vol. 120, pp. 234$241,2015$.

[17] A. A. van der Meer, M. Ndreko, M. Gibescu, and M. A. van der Meijden, "The effect of FRT behavior of VSC-HVDC-connected offshore wind power plants on AC/DC system dynamics," IEEE Trans. Power Del., vol. 31, no. 2, pp. 878-887, Apr. 2016.

[18] A. Moawwad, M. S. E. Moursi, W. Xiao, and J. L. Kirley, "Novel configuration and transient management control strategy for VSCHVDC," IEEE Trans. Power Systs., vol. 29, no. 5, pp. 2478-2488, Sep 2014

[19] L. Xu, L. Yao, and C. Sasse, "Grid integration of large DFIG-based wind farms using VSC transmission”, IEEE Trans. Power Syst., vol. 22 no. 3, pp. 976-984, Aug. 2007.
[20] J. N. Sakamuri, Z. H. Rather, J. Rime, M. Altin, O. Goksu, and N. A. Cutululis, "Coordinated voltage control in offshore HVDC connected cluster of wind power plants," IEEE Trans. Sustain. Energy, vol. 7, no. 4, pp. 1592-1601, Oct. 2016

[21] K. Schönleber, C. Collados, R. T. Pinto, S. Ratés-Palau, and O. GomisBellmunt, "Optimization-based reactive power control in HVDCconnected wind power plants," Renewable Energy, vol. 109, pp. 500$509,2017$.

[22] K. Schönleber, S. Ratés-Palau, M. De-Prada-Gil, and O. GomisBellmunt, "Reactive power optimization in HVDC-connected wind power plants considering wake effects," 14th Wind Integr. Work, Energynautics GmbH, Brussels, 2015.

[23] B. Zhang, P. Hou, W. Hu, M. Soltani, C. Chen, and Z. Chen, "A Reactive Power Dispatch Strategy With Loss Minimization for a DFIGBased Wind Farm," IEEE Trans. on Sustain. Energy, vol. 7, no. 3, pp. 914-923, Jul. 2017

[24] S. M. Muyeen, R. Takahashi, and J. Tamura, "Operation and control of HVDC-connected offshore wind farm," IEEE Trans. Sustain. Energy, vol. 1, no. 1, pp. 30-37, Apr. 2010.

[25] A. J. Sguarezi Filho, M. E. de Oliveira Filho, and E. Ruppert Filho, "A predictive power control for wind energy," IEEE Trans. Sustain. Energy, vol. 2, no. 1, pp. 97-105, Jan. 2011.

[26] V. Yaramasu, B. Wu, M. Rivera, and J. Rodriguez, "A new power conversion system for megawatt PMSG wind turbines using four-leve converters and a simple control scheme based on two-step model predictive strategy_Part I: Modeling and theoretical analysis," IEEE J. Emerging Sel. Topics Power Electron., vol. 2, no. 1, pp. 3-13, Mar. 2014

[27] X. Liu and X. Kong, "Nonlinear model predictive control for DFIG based wind power generation," IEEE Trans. Automat. Sci. Eng., vol. 11, no. 4, pp. 1046-1055, Oct. 2014.

[28] J. Hu, J. Zhu, and D. Dorrel, "Predictive direct power control of doubly fed induction generators under unbalanced grid voltage conditions for power quality improvement," IEEE Trans. Sustain. Energy, vol. 6, no. 6, pp. 687-695, Aug. 2014.

[29] H. Zhao, Q. Wu, Q. Guo, H. Sun, and Y. Xue, "Distributed model predictive control of a wind farm for optimal active power control-Part I: Clustering-based wind turbine model linearization," IEEE Trans. Sustain. Energy, vol. 6, no. 3, pp. 1-10, Jul. 2015

[30] H. Zhao, Q. Wu, Q. Guo, H. Sun, and Y. Xue, "Distributed model predictive control of a wind farm for optimal active power control-Part II: Implementation with clustering-based piece-wise affine wind turbine model," IEEE Trans. Sustain. Energy, vol. 6, no. 3, pp. 1-10, Jul. 2015.

[31] H. Zhao, Q. Wu, J. Wang, Z. Liu, S. Mohammad, Y. Xue, "Combined active power and reactive power control of wind farms based on mode predictive control," IEEE Trans. Energy Convers., to be published.

[32] E. Camponogara, D. Jia, B. H. Krogh, and S. Talukdar, "Distributed model predictive control," IEEE Control Syst. Mag., vol. 9, no. 1, pp. 44-52, Jan. 2002.

[33] K. Christakou, J. LeBoudec, M. Paolone, and D.-C. Tomozei, "Efficient computation of sensitivity coefficients of node voltages and line currents in unbalanced radial electrical distribution networks," IEEE Trans. Smart Grid, vol. 4, no. 2, pp. 741-750, Jun. 2013.

[34] E. V. Larsen and A. S. Achilles, "System and method for voltage control of wind generators," US Patent App. 14/018482, Sep.5 2013.

[35] S. Cole, J. Beerten, and R. Belmans, "Generalized dynamic VSC MTDC model for power system stability studies," IEEE Trans. Power Syst., vol. 25, no. 3, pp. 1655-1662, Aug. 2010.

[36] P. Lagonotte, J. C. Leost, and J. P. Paul, "Structural analysis of the electrical system: Application to secondary voltage control in France," IEEE Trans. Power Syst., vol. 4, no. 2, pp. 479-486, May. 1989.

[37] H. J. Ferreau, "Model predictive control algorithms for applications with millisecond timescales," Ph.D. thesis, Dept. of Electr. Eng., KU Leuven, Leuven, Belgium, 2011

[38] J. D. Grunnet, M. Soltani, T. Knudsen, M. Kragelund, and T. Bak, "Aeolus toolbox for dynamic wind farm model, simulation and control," in Proc. Eur. Wind Energy Conf., 2010, pp. 1-6. 